\title{
Structural and functional changes in RNAse A originating from tyrosine and histidine cross-linking and oxidation induced by singlet oxygen and peroxyl radicals
}

\author{
Leinisch, Fabian; Mariotti, Michele; Hägglund, Per; Davies, Michael J.
}

Published in:

Free Radical Biology and Medicine

Link to article, DOI:

10.1016/j.freeradbiomed.2018.07.008

Publication date:

2018

Document Version

Peer reviewed version

Link back to DTU Orbit

Citation $(A P A)$ :

Leinisch, F., Mariotti, M., Hägglund, P., \& Davies, M. J. (2018). Structural and functional changes in RNAse A originating from tyrosine and histidine cross-linking and oxidation induced by singlet oxygen and peroxyl radicals. Free Radical Biology and Medicine, 126, 73-86. https://doi.org/10.1016/j.freeradbiomed.2018.07.008

\section{General rights}

Copyright and moral rights for the publications made accessible in the public portal are retained by the authors and/or other copyright owners and it is a condition of accessing publications that users recognise and abide by the legal requirements associated with these rights.

- Users may download and print one copy of any publication from the public portal for the purpose of private study or research.

- You may not further distribute the material or use it for any profit-making activity or commercial gain

- You may freely distribute the URL identifying the publication in the public portal 


\section{Author's Accepted Manuscript}

Structural and functional changes in RNAse A originating from tyrosine and histidine cross-linking and oxidation induced by singlet oxygen and peroxyl radicals

Fabian Leinisch, Michele Mariotti, Per Hägglund, Michael J. Davies

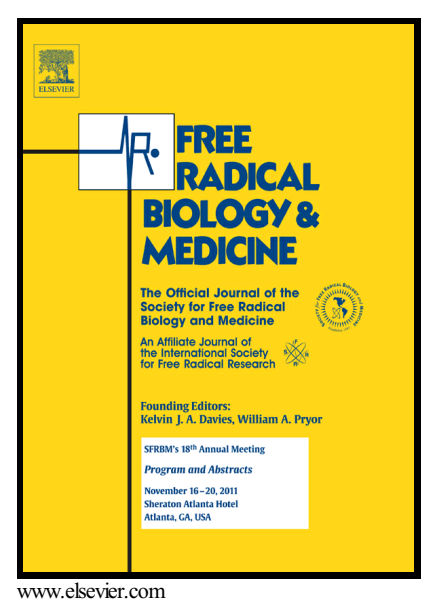

PII: $\quad$ S0891-5849(18)31235-8

DOI: $\quad$ https://doi.org/10.1016/j.freeradbiomed.2018.07.008

Reference: FRB13847

To appear in: Free Radical Biology and Medicine

Received date: 20 April 2018

Revised date: 12 July 2018

Accepted date: 16 July 2018

Cite this article as: Fabian Leinisch, Michele Mariotti, Per Hägglund and Michael J. Davies, Structural and functional changes in RNAse A originating from tyrosine and histidine cross-linking and oxidation induced by singlet oxygen and peroxyl radicals, Free Radical Biology and Medicine, https://doi.org/10.1016/j.freeradbiomed.2018.07.008

This is a PDF file of an unedited manuscript that has been accepted for publication. As a service to our customers we are providing this early version of the manuscript. The manuscript will undergo copyediting, typesetting, and review of the resulting galley proof before it is published in its final citable form. Please note that during the production process errors may be discovered which could affect the content, and all legal disclaimers that apply to the journal pertain. 


\title{
Structural and functional changes in RNAse A originating from tyrosine and histidine cross-linking and oxidation induced by singlet oxygen and peroxyl radicals
}

Fabian Leinisch ${ }^{1}$, Michele Mariotti $^{2}$, Per Hägglund ${ }^{1,2}$ and Michael J. Davies ${ }^{1^{*}}$

${ }^{1}$ Dept. of Biomedical Sciences, Panum Institute, University of Copenhagen, Copenhagen, Denmark;

${ }^{2}$ Department of Biotechnology and Biomedicine, Technical University of Denmark, Kongens Lyngby, Denmark

*Corresponding author. E-mail address: davies@sund.ku.dk (M.J. Davies)

\begin{abstract}
Oxidation can be induced by multiple processes in biological samples, with proteins being important targets due to their high abundance and reactivity. Oxidant reactions with proteins are not comprehensively understood, but it is known that structural and functional changes may be a cause, or a consequence, of disease. The mechanisms of oxidation of the model protein RNAse A by singlet oxygen $\left({ }^{1} \mathrm{O}_{2}\right)$ were examined and compared to peroxyl radical $\left(\mathrm{ROO}^{\circ}\right)$ oxidation, both common biological oxidants. This protein is a prototypic member of the RNAse family that exhibits antiviral activity by cleaving single-stranded RNA. RNAse A lacks tryptophan and cysteine residues which are major oxidant targets, but contains multiple
\end{abstract}


histidine, tyrosine and methionine residues; these were therefore hypothesized to be the major sites of damage. ${ }^{1} \mathrm{O}_{2}$ and $\mathrm{ROO}^{\bullet}$ induce different patterns and extents of damage; both induce cross-links and side-chain oxidation, and ${ }^{1} \mathrm{O}_{2}$ exposure modulates enzymatic activity. Multiple products have been characterized including methionine sulfoxide and sulfone, alcohols, DOPA, 2-oxohistidine, histidine-derived ring-opened species and inter- and intra-molecular cross-links (di-tyrosine, histidine-lysine, histidine-arginine, tyrosine-lysine). In addition to methionine modification, which appears not to be causative to activity loss, singlet oxygen also induces alteration to specific histidine, tyrosine and proline residues, including modification and crosslinking of the active site histidine, His12. The high homology among the RNAse family suggests that similar modifications may occur in humans, and be associated with the increased risk of viral infections in people with diabetes, as markers for ${ }^{1} \mathrm{O}_{2}$ have been found in early stages of this pathology. 
Graphical abstract:

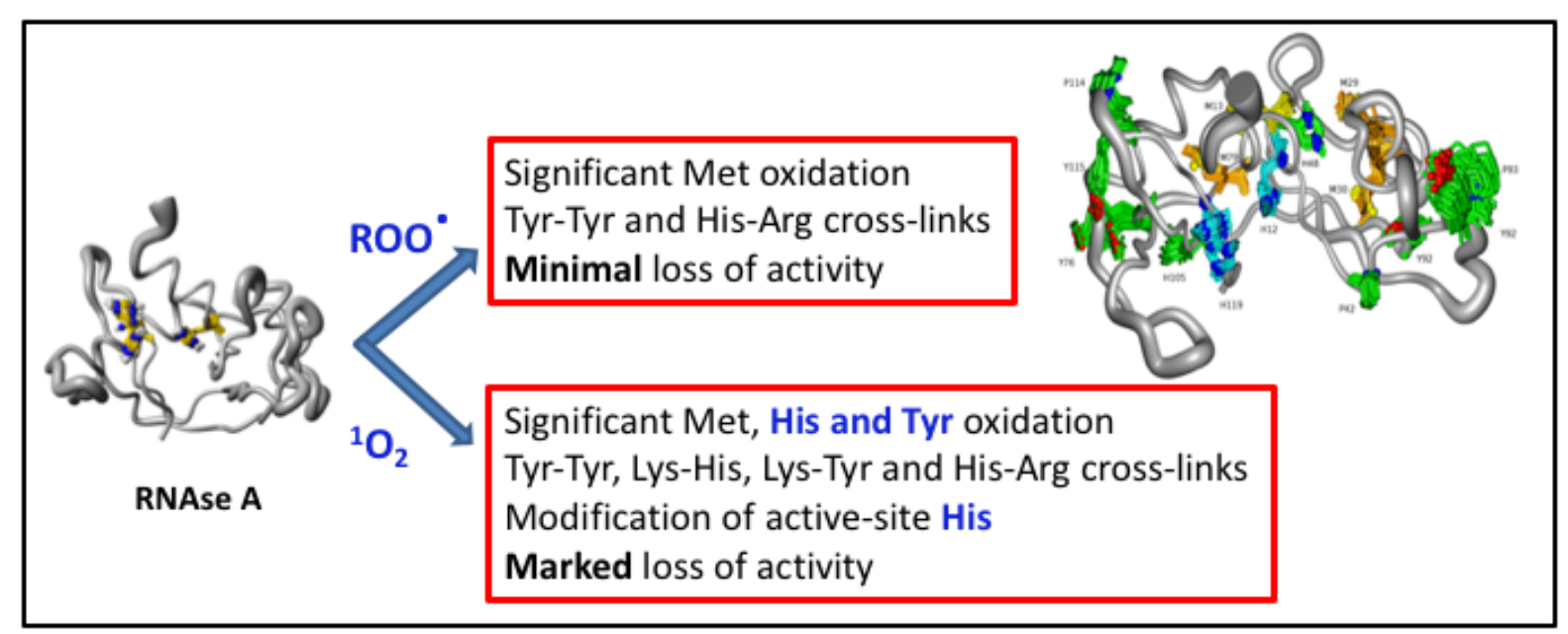

Abbreviations:

AAPH, 2,2'-azobis(2-amidinopropane) dihydrochloride; di-Tyr, the cross-linked species formed between two tyrosine residues, di-tyrosine; DOPA, 3,4-dihydroxyphenylalanine; MS, mass spectrometry, ${ }^{1} \mathrm{O}_{2}$, molecular oxygen in its first excited state ${ }^{1} \Delta_{\mathrm{g}} ; \mathrm{OPA}, \mathrm{o}$-phthaldialdehyde; PAGE, polyacrylamide gel electrophoresis; RNAse A, bovine pancreatic ribonuclease A (EC 3.1.27.5); ROO ${ }^{\bullet}$, aliphatic peroxyl radicals derived from thermal decomposition of AAPH in the presence of $\mathrm{O}_{2}$; SDS, sodium dodecylsulfate; UPLC, ultra high pressure liquid chromatography. 


\section{Keywords:}

Protein oxidation; singlet oxygen; peroxyl radicals; cross-linking; RNAse; proteomics; histidine; mass spectrometry

\section{Introduction}

Bovine pancreatic ribonuclease $A$ (RNAse $A$ ) is a pancreatic enzyme that cleaves single stranded RNA. It has been extensively studied since the 1940's, and has often been employed as a model protein to study protein folding, stability and activity [1]. This is due, at least in part to its high stability. It is a small ( $13.7 \mathrm{kDa}, 124$ residue) protein with a high content of basic residues (pl 9.6) as would be expected from its strong affinity to (negatively-charged) RNA [1]. The folding of the protein is maintained by four disulfide bonds, with the integrity of two of these pairs (Cys26 - Cys84 and Cys58 - Cys110) critical to maintenance of the folded state. The catalytic activity of the enzyme involves cleavage after pyrimidine nucleotides in single stranded RNA (ssRNA), with this reaction involving two histidine (His) residues (His12 and His119) positioned in a deep cleft on the protein surface where the RNA is bound [1].

The susceptibility of proteins to oxidation and inactivation depends on multiple factors, including its amino acid composition, the number and nature of the catalytic residues, the nature of the oxidizing species, and structural factors (e.g. accessibility) [2]. Bovine RNAse A does not contain any free cysteine (Cys) residues, which are a known and highly susceptible target for oxidants, nor any tryptophan (Trp) residues, which have a low radical reduction potential (i.e. are readily oxidized) [2,3]. However, it does contain 4 methionine (Met), 6 tyrosine (Tyr), 4 histidine (His) residues (including the two catalytic species), and 4 disulfide 
bonds [1], each of these species is known to be readily oxidized by some oxidants [2]. However, the role of damage to these species in inactivation of the enzyme is unclear, though it is known that oxidation can cause structural changes in RNAse A $[4,5]$. Oxidative cross-linking, as well as direct residue modification may be important, as it has been shown that the activity of crosslinked RNAse towards ssRNA is reduced by $40 \%$, and the effect on cleavage of double-stranded RNA (dsRNA) is even more marked [5]. It is known that Tyr oxidation can result in sidechain modifications with formation of both oxidized species such as 3,4-dihydroxyphenylalanine (DOPA and the corresponding quinone), and cross-links via the formation of dityrosine (diTyr) [6]. The chemistry of His oxidation is complex, but evidence has been presented for the formation of 2-oxo-His as initial intermediates which can undergo ring opening and further degradation [7,8], resulting in a large range of products [9-12]. Evidence has also been presented for a role of His residues in cross-linking, either via His-His linkages [9-11,13], or as a result of reaction of oxidized His species with nucleophiles e.g. amines / thiols $[9,14]$. Met residues are also well-established target for oxidants [15], with the corresponding sulfoxide being a major product, though other species such as the sulfone and side-chain degradation products, have also been reported [15-17]. Limited evidence has also been obtained for radicalmediated formation of Met-Met cross-links at the peptide level [18], and cross-links involving sulfimine bonds, arising from reaction of Met and Lys residues have also been reported $[19,20]$. Oxidation reactions are commonplace in biological systems due to wide range of both endogenous and exogenous processes that can give rise to these species [21]. These reactions can be initiated and propagated by both radicals (species with an unpaired electron) and twoelectron oxidants, with these species having different chemistries and selectivity. In the current 
study, we have examined one prototypical oxidant from each class: organic peroxyl radicals (ROO', generated by thermal decomposition of 2,2'-azobis(2-amidinopropane) dihydrochloride; AAPH), and singlet oxygen $\left({ }^{1} \Delta_{\mathrm{g}} \mathrm{O}_{2} ;{ }^{1} \mathrm{O}_{2}\right.$; generated by exposure of the photo-sensitizer Rose Bengal to visible light in the presence of $\mathrm{O}_{2}$ ). Both these oxidants are widely generated in biological systems with $\mathrm{ROO}^{\bullet}$ being important intermediates in many lipid and protein peroxidation reactions in presence of $\mathrm{O}_{2}[2,21]$, as a result of the rapid (typically diffusioncontrolled) reaction of $\mathrm{O}_{2}$ with carbon-centered radicals, and also the generation of these species from decomposition of hydroperoxides $[2,21,22] .{ }^{1} \mathrm{O}_{2}$ is a major intermediate in photochemical reactions (induced by both UV light, and visible light in the presence of a sensitizer, via Type II photo-chemical processes), in the reactions of peroxidase enzymes, via termination reactions of $\mathrm{ROO}^{\circ}$, and a range of chemical reactions (e.g. reaction of $\mathrm{H}_{2} \mathrm{O}_{2}$ with HOCl) $[23,24]$.

RNAse A lacks free Cys and Trp residues. Therefore, we hypothesized that reaction at Tyr, His and Met residues might predominate, and that reaction at these residues might result in cross-linking of the protein (e.g. via the formation of diTyr species, and possibly His-derived species), changes in structural integrity (fragmentation) and loss of activity, particularly if the oxidants reacted with the two His residues present in the active site of the enzyme. 


\section{Materials and Methods}

\subsection{Materials}

Chemicals and reagents were purchased from Sigma Aldrich (St Louis, MO). Chelex was from Biorad (Hercules, CA, USA). Di-tyrosine was from Toronto Research Chemicals (Toronto, CA). RNAse A (from bovine pancreas, $770 \mu \mathrm{M}, 10 \mathrm{mg} \mathrm{mL}^{-1}$ ) was dissolved in phosphate buffer (100 $\mathrm{mM}, \mathrm{pH}$ 7.4) made up with Milli-Q water and treated with Chelex-100 to remove trace metal ions.

\subsection{Photo-sensitized oxidation of RNAse A}

Oxidations were carried out as described previously $[25,26]$ with minor modifications. The protein solution was diluted with $\mathrm{D}_{2} \mathrm{O}(70 \% \mathrm{v} / \mathrm{v}$ final) to a final concentration of $250 \mu \mathrm{M}$ protein (3 $\mathrm{mg} \mathrm{mL}^{-1}$ ) in $10 \mathrm{mM}$ phosphate buffer, $\mathrm{pH}$ 7.4. Rose Bengal (10 $\mu \mathrm{M}$ final concentration) was added and samples were illuminated using a Leica P 150 slide projector through a polystyrene UV filter for $90 \mathrm{~min}$ at $4{ }^{\circ} \mathrm{C}$. Control samples were exposed for the same time in the absence of Rose Bengal, or incubated for the same period with Rose Bengal in the absence of light. The photon flux was determined as $2 \times 10^{16}$ photons $\mathrm{s}^{-1}$ using a $\mathrm{Ru}(\mathrm{BPY})_{3} \mathrm{Cl}_{2} /$ diphenylanthracene actinometer [27].

\subsection{Peroxyl radical (ROO ${ }^{\circ}$ ) -mediated oxidation of RNAse $A$}

$\mathrm{ROO}^{\bullet}$ mediated oxidation was carried out as described previously $[25,28]$, with minor modifications. Protein solutions $\left(250 \mu \mathrm{M}, 3 \mathrm{mg} \mathrm{mL}^{-1}\right.$ protein, $100 \mathrm{mM}$ phosphate buffer final 
concentrations) were incubated with 2,2'-azobis(2-amidinopropane) dihydrochloride (AAPH, 10 $\mathrm{mM}$ ) for $90 \mathrm{~min}$ at $40^{\circ} \mathrm{C}$ in the presence of $\mathrm{O}_{2}$ with continuous mixing at $400 \mathrm{rpm}$. Control samples were incubated in an identical matter in the absence of AAPH. The initial radical flux was estimated as $3 \times 10^{16}$ radicals s ${ }^{-1}$ at $40^{\circ} \mathrm{C}$, by use of the first order rate constant for decomposition of AAPH [29]. Correction for the efficiency of escape of the initial carboncentred radicals from the solvent cage [30], gives a flux of "free" radicals of $\sim 1.4 \times 10^{16}$ radicals $\mathrm{s}^{-1}$ and therefore $1.38 \mu \mathrm{M} \mathrm{min}$.

\subsection{SDS-PAGE and Western blotting}

Control and oxidized proteins samples (16 $\mu \mathrm{g}$ protein per well) were prepared under reducing conditions and loaded on 4 - 12\% Bis-Tris acrylamide gels (Invitrogen, Carlsbad, CA), and electrophoresed at $200 \mathrm{~V}$ for $40 \mathrm{~min}$. After electrophoresis, gels were stained with colloidal Coomassie Blue [31].

\subsection{Determination of RNAse A enzyme activity}

The activity of RNAse A was determined by quantification of its capacity to carry out enzymatic hydrolysis of ribonucleic acid from baker's yeast. Activity (Kunitz units) were calculated for both parent (un-oxidized) and oxidant-treated samples of RNAse A, by monitoring the change in absorbance at $300 \mathrm{~nm}$ by UV-Vis spectroscopy [32]. Measurements of changes in absorbance and UV-Vis spectra of the reaction mixtures were recorded using a Labomed UVD-2950 spectrophotometer. 


\subsection{Amino acid analysis by UPLC with fluorescence detection}

Samples were prepared as described above and before $[25,33]$ with $200 \mu \mathrm{L}$ of the reaction mixtures and controls transferred to glass hydrolysis vials, and the protein precipitated using 50 $\mu \mathrm{L}$ of $50 \%$ aqueous trichloroacetic acid, washed twice with acetone, and dried using a stream of nitrogen gas. $150 \mu \mathrm{L}$ of $4 \mathrm{M}$ methanesulfonic acid containing $0.2 \% \mathrm{w} / \mathrm{v}$ tryptamine was added, the samples deoxygenated, and then incubated under vacuum at $110^{\circ} \mathrm{C}$ overnight using a Pico-Tag system. After cooling, the samples were neutralized with $\mathrm{NaOH}$, filtered through 0.2 $\mu \mathrm{m}$ Pall Nanosep filters and diluted 4-fold with water. Diluted samples $(30 \mu \mathrm{L})$ were transferred to HPLC vials and subjected to UPLC using a Shimadzu Nexera system equipped with a SIL-30AC autosampler (with the samples kept at $4^{\circ} \mathrm{C}$ ) and a RF-20A XS fluorescence detector. Samples were then derivatized by adding $10 \mu \mathrm{L}$ of $o$-phthaldialdehyde (OPA) solution (Fisher) and incubated for $1 \mathrm{~min}$, before injection $(4 \mu \mathrm{L}$ ) on to a reversed phase column (Phenomenex Kinetex; $2.6 \mu \mathrm{m}$ EVO $150 \times 3 \mathrm{~mm}$ maintained at $40^{\circ} \mathrm{C}$ ). Samples were eluted using a gradient (see Supplementary Table 1) of buffer A (100 mM sodium acetate pH 5.3, $2.5 \%$ tetrahydrofuran, $20 \%$ methanol in water) and B (100 mM sodium acetate $\mathrm{pH} 5.3,2.5 \%$ tetrahydrofuran, $80 \%$ methanol in water), at a flow rate of $0.8 \mathrm{~mL} \mathrm{~min}^{-1}$. Fluorescence was monitored using $\lambda_{\mathrm{ex}} 340 \mathrm{~nm}, \lambda_{\mathrm{em}} 440 \mathrm{~nm}$. Data analysis was carried using Shimadzu Lab Solutions Browser. Standards were run under identical conditions to identify eluting species, and to construct standard curves, from which concentrations were determined. To minimize concentration variations arising during the protein hydrolysis, the data were normalized to the concentration of Ala residues. 


\subsection{Detection and quantification of oxidation products by UPLC}

Protein samples were hydrolyzed and neutralized as described above, then analyzed as reported previously $[25,33]$. Samples $(4 \mu \mathrm{L})$ were injected on to reversed phase column (Phenomenex Kinetex, $2.6 \mu \mathrm{m}$ EVO $150 \times 3 \mathrm{~mm}$ ) thermostated at $30^{\circ} \mathrm{C}$, and separated by gradient elution at $0.8 \mathrm{~mL} \mathrm{~min}^{-1}$ using buffer $\mathrm{A}\left(100 \mathrm{mM}\right.$ sodium perchlorate, $10 \mathrm{mM} \mathrm{H}_{3} \mathrm{PO}_{4}$ ) and buffer B ( $80 \%$ aqueous methanol) [25]. Eluted materials were monitored using 2 fluorescence detector channels parametrized according to the retention times of the products and their fluorescence maxima [25]. Data analysis was carried out with Shimadzu Lab Solutions Browser software. Assignments were based on fluorescence data, retention times and comparison to the authentic standards, with concentrations were determined by use of standard curves. To compensate for any losses during processing, data are expressed relative to parent Tyr.

\subsection{Mass spectrometric analysis of oxidation products}

Oxidation products were determined on peptides generated by tryptic digestion [34]. Triplicate samples (150 $\mu$ g protein prepared as described above) were transferred onto spin filters (10 $k D a$ cut-off), with the buffer then removed by centrifugation, and replaced with $100 \mu \mathrm{L}$ of 100 $\mathrm{mM}$ ammonium bicarbonate buffer ( $\mathrm{ABC}$ buffer) which was again removed by centrifugation. Reduction and alkylation was carried out by adding $100 \mu \mathrm{L}$ of a solution containing $10 \mathrm{mM} \mathrm{TECP}$ and $40 \mathrm{mM}$ chloroacetamide solution in $\mathrm{ABC}$ buffer, with the samples then incubated for 10 min at $95{ }^{\circ} \mathrm{C}$ with stirring at $500 \mathrm{rpm}$. The alkylation solution was subsequently removed by centrifugation, $30 \mu \mathrm{L}$ of trypsin solution $(3 \mu \mathrm{g})$ in $\mathrm{ABC}$ buffer with $0.2 \%$ deoxycholic acid was added, and samples were incubated overnight at $37^{\circ} \mathrm{C}$ with stirring at $500 \mathrm{rpm}$. One hundred $\mu \mathrm{L}$ 
of Milli-Q water was then added and tryptic peptides collected by centrifugation. The deoxycholic acid was precipitated by addition of $1 \mu \mathrm{L}$ formic acid solution (1\%; $265 \mathrm{mM})$, with the samples then centrifuged. Fifty $\mu \mathrm{L}$ of the supernatant was transferred into HPLC vials with insets for MS analysis.

Samples were analyzed on a Bruker Impact II ESI-QTOF (Bruker Daltonics) mass spectrometer after separation using a Dionex Ultimate 3000 chromatography system (Thermo Fisher Scientific) equipped with an Aeris Peptide XB C18 Column $(25 \mathrm{~cm}, 2.6 \mu \mathrm{m}$ particle size, $2.1 \mathrm{~mm} \mathrm{ID)}$. Samples were eluted using a solvent gradient system over $80 \mathrm{~min}$, using acetonitrile with $0.1 \%$ formic acid and $2.5 \%$ dimethyl sulfoxide at a flow rate of $200 \mu \mathrm{L} \mathrm{min}^{-1}$. Sampling rate was $2 \mathrm{~Hz}$ for MS and 4-16 Hz for MS/MS (IDAS, top20), and a scan range of 150 to $1500 \mathrm{~m} / \mathrm{z}$ was applied.

Data analysis was performed using MaxQuant (version 1.5.3.30) $[35,36]$ with semispecific tryptic constraints and a $1 \%$ peptide level false discovery rate. Carbamidomethyl of cysteine was used as a fixed modification. Data was filtered in order to extract peptidespectrum matches corresponding to established oxidative modifications using a list of known oxidative modifications [37], with changes to Met, His, Tyr and Pro used as variable modifications, as described elsewhere [38]. The extent of modification at a particular site was estimated based on label-free quantification of the abundance ratios of the corresponding modified and non-modified peptides, present in the detected sequence of the protein (i.e. omitting those amino acids not observed), as determined using MaxQuant. Peaks with abundance changes of $>10 \%$ were evaluated in respect to elution times, isotopic distribution and MS/MS profiles using Skyline [39]. 


\subsection{Analysis of cross-link formation by mass spectrometry}

Mass spectrometric analysis for the identification of cross-linked peptides was performed essentially as described previously $[25,40]$. Briefly, tryptic peptides digested in ${ }^{18} \mathrm{O}$ - and ${ }^{16} \mathrm{O}$ water were mixed and immediately separated on an EASY nLC 100 chromatograph coupled to an Orbitrap Fusion mass spectrometer (Thermo Fisher). Data was acquired either with a universal method characterized by a full MS Orbitrap scan followed by data-dependent highenergy collisional dissociation (HCD) MS/MS scans, or a data-dependent method where a group of signals displaying mass shifts of 4, 6 and 8 Da are selected for MS/MS. Cross-linked peptides were identified using the software MassAl (Univ. of Southern Denmark, April 2017) with the following settings; fixed (carbamidomethylation of Cys) and variable (Met, His, and Tyr oxidation) modifications; maximum 2 missed tryptic cleavages; parent mass tolerance 10 ppm; MS/MS peak tolerance $0.02 \mathrm{~m} / \mathrm{z}$. Di-tyrosine (Tyr-Tyr), lysine-tyrosine (Lys-Tyr), lysine-histidine (Lys-His), histidine-histidine (His-His), and arginine-histidine (Arg-His) were selected as potential cross-links.

\subsection{Rendering of protein structures}

Protein structures were visualized and distance distributions were obtained using the program MolMol [41] using scripts generated in GNU Octave [42] , and the PDB structure 2AAS, which consists of 32 NMR coordinate sets for the bovine RNAse A monomer [43]. For distance distributions, all mesomers/chemically equivalent atoms of the same coordinate set capable of 
forming the cross-link detected by mass spectrometry were considered, resulting in a sample size of 32-128. To calculate histograms, a bin size was $0.5 \AA$ was chosen.

\subsection{Statistics}

Data are presented as means + standard deviations from at least three replicate independent experiments, with errors propagated when data are normalized to another parameter. Statistical analysis was carried out using the packages available in Excel with $P<0.05$ taken as indicating statistical significance.

\section{Results}

SDS-PAGE evidence for RNAse A cross-linking induced by ${ }^{1} \mathrm{O}_{2}$ and $\mathrm{ROO}^{\circ}$

Exposure of RNAse to a complete system consisting of Rose Bengal (10 $\mu \mathrm{M})$, visible light and $\mathrm{O}_{2}$ in buffer made up using $70 \% \mathrm{D}_{2} \mathrm{O}$ (to enhance the lifetime of ${ }^{1} \mathrm{O}_{2}$ ), and subsequent separation of the samples on gels under reducing conditions and staining with Coomassie Blue, resulted in the detection of dimers and higher oligomers with increasing light exposure time (Fig. 1A-C). Gels were not run under non-reducing conditions due to the absence of Cys residues in the protein. The untreated parent protein sample (Fig. 1A) ran as one major band at a slightly higher mass than expected on the basis of its protein sequence (see PDB structure 2AAS) probably as a result of its high content of positive charges which results in increased interactions between SDS and the protein; this is a well-established phenomenon with some proteins [44]. An additional minor band of higher mass was detected slightly above the main 
parent protein band; this is ascribed to incomplete cleavage of the pro- (signal) peptide from the parent protein. The weak band detected at the bottom of the gel is assigned to the cleaved signal peptide. A weak band was also detected at a mass approximately double that of the parent protein, with this ascribed to low levels of dimers present in the commercial samples. The intensity of this dimer band, and the appearance of additional bands assigned to a trimer and tetramer, increased with longer light exposure times in the presence of Rose Bengal and $\mathrm{O}_{2}$. Omission of the Rose Bengal (i.e. exposure of the protein to visible light and $\mathrm{O}_{2}$ alone) markedly decreased the extent of oligomerization (Fig. 1A). Samples that contained Rose Bengal and $\mathrm{O}_{2}$ but which were not overtly exposed to light, showed low levels of dimer formation, probably as a result of exposure to stray light during sample preparation and analysis (Fig. 1A).

Addition of Rose Bengal to RNAse, at the same concentrations, but in the absence of light, and subsequent examination by UV/visible spectroscopy did not provide evidence for a marked shift in the absorption maximum of the dye molecule $\left(\lambda_{\max } \sim 550 \mathrm{~nm}\right)$, suggesting that the dye does not bind strongly to the protein. There was however a decrease in the absorbance intensity compared to the dye alone, possibly as a result of quenching by the protein (Supplementary Fig. 1).

Exposure of RNAse A to ROO ${ }^{\circ}$ formed by thermal decomposition of AAPH $\left(10 \mathrm{mM}, 40^{\circ} \mathrm{C}\right.$, $90 \mathrm{~min}$ ) also resulted in the formation of oligomers (Fig. 1A,B,D), when compared to control samples of protein incubated under identical conditions in the absence of AAPH. This occurred to a more limited extent than observed with the Rose Bengal/light/ $\mathrm{O}_{2}$ system (Fig. 1B). The differences between these two oxidant systems, even though the conditions chosen generate 
approximately similar levels of $\mathrm{ROO}^{\bullet}$ as photons from the visible light / Rose Bengal system (see Materials and methods) [25], suggests major differences in the extent and / or type of damage induced on the RNAse A.

The presence of the spin trap DMPO $(10 \mathrm{mM})$, which is known to react with protein radicals and $\mathrm{ROO}^{\bullet}$ [45], decreased the extent of oligomer formation (Supplementary Fig. 2), consistent with radical-mediated dimer formation. In contrast, the same concentration of DMPO had minimal effects on the extent of oligomer formation in the Rose Bengal/light $/ \mathrm{O}_{2}$ system (Supplementary Fig. 2).

\section{Effect of oxidant exposure on enzyme activity}

To examine the effect of oxidation to the enzymatic activity of RNAse A, the hydrolysis of ribonucleic acid was monitored by UV/Vis spectroscopy as the decrease in absorbance at 300 $\mathrm{nm}$, and the Kunitz units of activity per mg protein were calculated (Fig. 2A,B). With native enzyme rapid hydrolysis of the added RNA was detected under the conditions employed. Whilst exposure to ROO ${ }^{\circ}$ generated by thermal decomposition of $\mathrm{AAPH}\left(10 \mathrm{mM}, 40^{\circ} \mathrm{C}, 90 \mathrm{~min}\right)$ did not induce any significant change in activity, exposure to ${ }^{1} \mathrm{O}_{2}$ generated by the Rose Bengal/visible light $/ \mathrm{O}_{2}$ (as described above) resulted in an $80 \%$ decrease in enzymatic activity (Fig. $2 \mathrm{~A}, \mathrm{~B}$ ). In absence of the RNAse A (Fig. 2B), neither oxidant system showed significant RNAse activity.

\section{Detection and quantification of amino acid oxidation on RNAse A.}

The nature of the amino acids modified by the two oxidant systems and the products formed from these reactions was examined by amino acid analysis using UPLC with fluorescence 
detection (Supplementary Fig. 3), LC-MS analysis of peptide digests (Fig. 3A), and UPLC analysis of specific oxidation products (Fig. 3B). These methods give complementary data. The amino acid composition determined experimentally by UPLC agreed well with the expected (theoretical, from amino acid sequence) values (Supplementary Fig. 4). Of the amino acid residues detected by total amino acid analysis with $o$-phthaldialdehyde tagging (see Material and methods), significant changes were detected in the levels of Met, His and Tyr, with lower levels of modification detected on other amino acids (Supplementary Fig. 3). This method does not however allow quantification of modification to cysteine or proline (Pro). A concomitant increase in methionine sulfoxide was detected (Supplementary Fig. 3). The overall extent of modification of the detected amino acids was much larger with the ${ }^{1} \mathrm{O}_{2}$ system compared to $\mathrm{ROO}^{\circ}$, as judged by the total number of moles of amino acids modified.

The LC-MS analysis, which was constricted to the detection of Met, His, Tyr and Pro modifications to reduce the complexity of the data analysis, confirmed the higher overall extent of alteration seen with the ${ }^{1} \mathrm{O}_{2}$ system compared to ROO ${ }^{\bullet}$ (Fig. 3). Of the modifications detected by MS, the majority of the modifications corresponded to the addition of a single oxygen atom (i.e. $m / z+16$ compared to the parent ion), with this presumed to be due to the formation of the sulfoxide from Met (as seen with the amino acid analysis), the formation of 3,4dihydroxyphenylalanine (DOPA) from Tyr, and the formation of hydroxylated (alcohol) species from Pro. Low levels of a $m / z+32$ species were detected for Met, with this presumed to be due to sulfone formation. In the case of His, significant levels of a $m / z-10$ species were also detected in addition to a $m / z+16$ (alcohol) species, and low levels of a species with $m / z-22$. The $m / z-10$ species is assigned to the established His degradation product aspartylurea, and 
the $m / z-22$ species to aspartic acid, arising from cleavage of the imidazole ring of the His side chain, and sequential degradation (Fig. 3B).

Further analysis of the Tyr oxidation products was carried out using UPLC with oxidation products detected by fluorescence spectroscopy [25]. This approach allowed quantification of the total extent of Tyr consumption, and specific species arising from these reactions (Fig. 3C, Supplementary Fig. 5). A much greater overall extent of loss was detected with the ${ }^{1} \mathrm{O}_{2}$ system ( $\sim 10 \%$ loss compared to $\sim 2.5 \%$ with ROO ${ }^{\bullet}$; Fig. $3 \mathrm{C}$ and also below) but only low levels of the material consumed could be accounted for with DOPA being the major assignable product with the ${ }^{1} \mathrm{O}_{2}$ system and di-Tyr being the major assignable product with the ROO ${ }^{\bullet}$ system. In both cases however a significant amount of the lost parent could not be accounted for (Fig. 3C).

For the four amino acids observed to be modified to a significant extent by the two oxidants, the average extent of modification was calculated as the sum of all detected modification percentages, normalized by the number of residues. For the ROO ${ }^{\bullet}$ system, Met was the most extensively oxidized as judged by the data for Met sulfoxide from both the MS experiments ( $18.5 \%)$, and amino acid analysis ( $30 \%)$. The extent of parent Met loss in the amino acid analysis could not be accurately quantified for this oxidant, due to a co-eluting peak. His was the next most readily modified, with the values for the extent of modification being markedly different between the method employed ( $16 \%$ loss by amino acid analysis vs. $\sim 1 \%$ detection of products by MS), with this discrepancy likely to arise from an incomplete knowledge of the products arising from His degradation, preventing complete MS analysis). Tyr was modified to $<1 \%$ as judged by MS product analysis and by $\sim 5 \%$ by amino acid loss. All the other amino acids (of those examined) had modification levels of $<1 \%$. 
For the ${ }^{1} \mathrm{O}_{2}$ system, Met oxidation was the most significant in terms of $\%$ change, as judged by both loss of the parent amino acid ( $36 \%$ by amino acid analysis and $57 \%$ by MS) and Met sulfoxide formation ( $51 \%$ by MS and $29 \%$ amino acid analysis). For His, a consumption of $8 \%$ (MS) vs. $41 \%$ (by amino acid analysis) was detected, with the discrepancy likely to be due to similar reasons as outlined above. For Tyr, $5 \%$ conversion was detected by MS, and $\sim 10 \%$ by analysis of parent amino acid loss by UPLC. For the ${ }^{1} \mathrm{O}_{2}$ system evidence was also detected by MS (this amino acid is not readily tagged by $o$-phthaldialdehyde, and hence not detected using the amino acid analysis method employed) for modification of Pro at a level of $\sim 5 \%$, with this being detected as an alcohol $(m / z+16)$, though the position of this on the ring is unknown.

\section{Detection and identification of intra- and inter-molecular cross-links}

The potential formation of Tyr- and His- based cross-links as a result of oxidation was investigated by making use of the addition mass differences found in cross-linked peptides which contain two carboxyl termini after trypsin digestion in $\mathrm{H}_{2}{ }^{18} \mathrm{O}$ compared to $\mathrm{H}_{2}{ }^{16} \mathrm{O}$. Consequently, distinctive peaks differing by $4 \mathrm{Da}$ are yielded in the parent mass spectra (i.e. +4 Da for non-cross-linked peptides compared to +8 Da for cross-linked peptides, resulting from the incorporation of $4{ }^{18} \mathrm{O}$ atoms at the two $\mathrm{C}$-termini of the cross-linked peptides), which indicate the presence of the cross-link. In total, six cross-linked peptides were identified, including one containing a di-Tyr linkage, one Lys-Tyr, two His-Arg and one His-Lys. Strong evidence has been found for the di-Tyr cross-linked peptide (NGQTNCYQSYSTMSITDCR) (ETGSSKYPNCAYK), in RNAse exposed to ${ }^{1} \mathrm{O}_{2}$ with the cross-link formed between Tyr73 and Tyr92. This cross-linked peptide showed the expected -2.01 Da mass difference compared to 
the sum of the two parent peptides, due to the Tyr-Tyr (Y-Y) cross-link, with the theoretical mass (3786.567 Da) matching closely to the experimental mass (3786.554 Da; ppm mass error 3.4). Analysis of the MS/MS spectrum (Fig. 4A) revealed that several fragment ions retain the cross-link site (y13-y17 and b7-b12 ions for the (longer) $\alpha$ peptide, and y8 for the (shorter) $\beta$ peptide, providing compelling evidence for this linkage.

A Lys-Tyr cross-link was also identified in ${ }^{1} \mathrm{O}_{2}$-exposed RNAse involving Lys37 and Tyr 92 in the peptides (SRNLTKDR) (ETGSSKYPNCAYK). The mass loss (-2.01 Da) compared to the sum of the parent sequences is consistent with this type of cross-link, with the theoretical mass (2506.185 Da) corresponding closely to the experimental mass (2506.173 Da; ppm mass error 4.78). Further evidence for this link is present in the corresponding MS/MS spectrum (Fig. 4B), which indicates that the $y 7$ ion for the $\alpha$ peptide and the $y 5-y 6$ ions for the $\beta$ peptide, retain the cross-link site.

A further cross-link involving Arg33 and the active site His12 residue, was also detected after ${ }^{1} \mathrm{O}_{2}$ exposure between the peptides (SRNLTKDR) (RQHMDSSTSAASSSNYCNQMMK). The overall mass increase of +13.98 Da compared to the sum of the two parent peptides, is consistent with a His-Arg cross-link (experimental mass 3538.529 Da compared to theoretical mass 3538.542 Da; 3.767 ppm difference). The MS/MS of this cross-linked peptide (Fig. 4C) shows that $b 3-b 12, b 14-15$ ions for the $\alpha$ peptide, and b2, b5-b7 ions for the $\beta$ peptide, retain the cross-link site therefore providing strong evidence for this cross-link. A His-Lys cross-link was also detected on ${ }^{1} \mathrm{O}_{2}$ exposure, in the peptide pair (CKPVNTFVHESLADVQAVCSQK) (KETAAAKFER) linking His48 and Lys1 (Supplementary Fig. 6A). The mass increase of +13.98 Da 
compared to the sum of the two parent peptides is consistent with a His-Lys cross-link (experimental mass 3679.802 compared to theoretical mass 3247.809; 1.9 ppm difference). The MS/MS spectrum of this peptide showed coverage for both peptides and provides strong evidence for this cross-link.

For the ROO ${ }^{\bullet}$ oxidation system, two cross-links were detected. Firstly, an alternative HisArg cross-link to that seen with ${ }^{1} \mathrm{O}_{2}$ (see above) was identified between the peptides (CKPVNTFVHESLADVQAVCSQK) (SRNLTK), linking His48 and Arg33 (experimental mass 3247.595 Da compared to theoretical mass 3247.608 Da; 4 ppm difference, Supplementary Fig. 6B). Secondly, a di-Tyr cross-link involving the peptides (YPNCAYK) (HIIVACEGNPYVPVHFDASV), where Tyr92 and Tyr115 are cross-linked (experimental mass 3167.444 Da compared to theoretical mass 3167.446 Da; 1 ppm difference, Supplementary Fig. 6C).

\section{Mapping of amino acid oxidation sites on RNAse A}

The MS data was also used to map the oxidative modifications to specific sites in the primary structure of the protein for both oxidant systems. Only very low levels of Met oxidation $(<3 \%)$ were detected in control samples from both oxidant systems (Supplementary Fig. 7) Localization of the respective species was verified by analysis of the $y$ and $b$ ions of the MS-MS spectra (Supplementary Fig. 8).

For the ROO ${ }^{\bullet}$ system, oxidation at each of the four Met residues present in the RNAse A sequence were detected with moderate levels of modification, with this ranging between $12-23$ \% for individual sites (Fig. 5: Met13, $12 \%$; Met29, 22\%; Met30, $18 \%$; Met79, 23\%). The relatively narrow range of these values suggests that none of these residues is particularly 
prone or favored for oxidation by this radical. The non-oxidized but incubated, control samples showed significantly less modification (0 \% - $3 \%$, with the highest value detected for Met29). The modifications detected at His were primarily localized to two of the four residues present in the protein): His12 (one of the two His residues involved in catalysis), and His48. The latter residue is also involved in one of the identified cross-links with Arg33 (see above). Modification to Tyr was also detected at two (out of the 6) Tyr residues present in the enzyme): at Tyr115 (which was detected as a $m / z+16$ species), and at Tyr92 as part of a cross-link with Tyr115 (see above and Supplementary Fig. 6).

For the ${ }^{1} \mathrm{O}_{2}$ system, both the overall degree of modification was higher, but damage was also detected at a greater number of sites (Fig. 6). Met residues were again the most extensively modified amino acid, with the extent of conversion to Met sulfoxide $(\mathrm{m} / \mathrm{z}+16)$ being $49 \%$ - $70 \%$ across all of the Met residues (Met13, $49 \%$; Met29, $66 \%$; Met30, $48 \%$; Met79, 45\%). Modest amounts of a $m / z+32$ species, presumed to be the sulfone, were also detected at some of these sites with the highest levels detected at Met79 (Met29, $4 \%$; Met30, $5 \%$; Met79, $9 \%$ ). His modification was detected at three of the 4 residues present in the protein, with the most significant levels of modification detected at His12 ( $12 \%$, with this almost exclusively a $m / z+16$ species), His 48 ( $18 \%$, with this being mostly detected as $m / z-10$ and $m / z-22$ species, with the formed predominating) and at His119 ( $2 \%$ and mostly $m / z+16$ ). These data suggest considerable variation in both the ease of oxidation of the 4 His residues and the nature of the oxidation processes that occur. Tyr modifications were found on four of the 6 residues present, with Tyr25 and Tyr73 each modified to $m / z+16$ (presumed to be DOPA) at $\sim 5 \%$, whereas Tyr92 and Tyr97 were oxidized, also to $\mathrm{m} / \mathrm{z}+16$ species, to $\sim 7$ and $\sim 11 \%$ 
respectively. No convincing evidence was obtained for oxidation at Tyr76 and Tyr115 (i.e. modification extents of $<1 \%$ ). Interestingly, significant modification was also detected at Pro42 ( $22 \%$ modification to a $\mathrm{m} / \mathrm{z}+16$ species) and Pro117 ( $2 \%, \mathrm{~m} / \mathrm{z}+16)$. A number of these residues are also involved in the cross-links described above (His12-Arg33, Lys1-His48, Lys37Tyr92, and Tyr73-Tyr92).

\section{Discussion}

In this study, we have investigated the effects of two common oxidants, the two-electron excited state species ${ }^{1} \mathrm{O}_{2}$, and peroxyl radicals (ROO*), on an extensively investigated model protein bovine pancreatic RNAse A. This enzyme is widely regarded as being highly stable, and contains 4 disulfide bonds that play a key role in stabilizing the folded form [1]. It is known to retain its activity after being subjected to intense heat stress (boiling buffer), most likely due to facile and rapid refolding after heat denaturation [1]. The protein does not contain two of the major targets for oxidants - free Cys and Trp - but does contain relatively high levels of His and Tyr ( 4 and 6 residues, respectively) and has a low content of hydrophobic residues. Most of the residues in the protein are surface exposed, due to the presence of a deep and wide cleft across the middle of the protein structure that acts as the binding site for RNA substrates (cf. PDB structure: 2AAS [43]). This cleft contains a significant number of positively-charged residues that interact with the phosphate backbone of single-stranded RNA which is the preferred substrate, though double-stranded RNA can also be cleaved. The enzymatic activity arises from two His residues (His12 and His119) present within the cleft with these cleaving the RNA after 
pyrimidine residues, via attack on a $3^{\prime}, 5^{\prime}$-phosphodiester bond of the ribose-phosphate backbone, with formation of a $2^{\prime}, 3^{\prime}$ cyclic intermediate, which is then hydrolyzed to give a new 3'-monophosphate species [1].

In the light of the known selectivity of ${ }^{1} \mathrm{O}_{2}$ and $\mathrm{ROO} 0^{\circ}$, which both preferentially target readily oxidized residues (e.g. Cys, Trp, His, Met, Tyr) [2,23,24], we hypothesized that His, Met and Tyr would be the major residues targeted in RNAse A due to the absence of Cys and Trp residues. As two of the His residues (12 and 119) are known to be critical to enzyme function [1], oxidation might therefore have marked effects on enzyme activity. Furthermore, both His and Tyr residues are known precursors of inter- and intra-molecular cross-links [2] and hence oxidation might impact on protein structure and function via formation of dimers and oligomers.

The data obtained by SDS-PAGE run under reducing conditions (non-reducing conditions were not examined due to the absence of any free Cys residues in the protein), provided evidence for the presence of dimers and higher oligomers with the extent of formation of these species dependent on the illumination time (for the Rose Bengal system) or the incubation time with AAPH (for the RO0*) system. For the former system, much lower levels of (or no) crosslinking were observed in the corresponding controls in which the Rose Bengal was omitted, where there was no light exposure, or both were excluded. The control protein samples showed the presence of further bands, in addition to that for the parent mature protein (Fig. 1). The band that is present consistently at slightly higher mass than the mature protein (Fig. 1) is assigned to the non-processed (pre-) protein that retains the signal peptide. The additional weak band at low mass molecular mass (Fig. 1B) is assigned to the released signal peptide. 
Evidence was also present in these control samples for low levels of a dimeric species (Fig. 1), but at much lower levels that in the oxidant treated samples.

For the Rose Bengal system, a significant amount of cross-linked material was detected in the samples immediately after exposure to light. Thus the " 0 min" sample, showed a peak at the mass of a tetramer ( $60 \mathrm{kDa})$, which decreased in intensity with increasing illumination time. Significant increases in the bands assigned to dimers and trimers were also observed over time (Fig. 1B,C). Similar bands were detected with the AAPH system but at much lower intensity. The suppression of oligomer formation by DMPO, in case of AAPH (ROO') oxidation but not with ${ }^{1} \mathrm{O}_{2}$ (Supplementary Fig. 2), is consistent with a major contribution of radicalmediated reactions to oligomer formation induced by AAPH, but not for sensitizer-mediated photoreaction.

The data obtained indicate that sensitizer-mediated oxidation with Rose Bengal, which is known to generate ${ }^{1} \mathrm{O}_{2}$ via Type II photo-oxidation reactions [46], gives rise to rapid and extensive loss of activity, concurrently with formation of dimers and higher oligomers (involving His, Tyr Lys and Arg residues, see further discussion below), as well as extensive modification to Met, His, Tyr and Pro residues. This pattern of damage is consistent with the formation and reactions of ${ }^{1} \mathrm{O}_{2}$, with the UV/visible spectra of the protein and Rose Bengal mixture showing no obvious evidence of the formation of tightly-bound protein-sensitizer complexes that might favor Type I photochemical reactions (i.e. direct electron transfer) [47,48]; the absorption maximum of the sensitizer in the presence of the protein showed a small bathochromic shift of $2 \mathrm{~nm}$ which is within the experimental error, and very much lower than the $>10 \mathrm{~nm}$ shifts reported in the literature for complex formation [47]. 
The ROO ${ }^{\bullet}$ system has been shown to induce different effects to the Rose Bengal system, even though the flux of intermediates (photons versus radical yield) under the experimental conditions chosen are similar in magnitude [25]. In the case of $\mathrm{ROO}^{\bullet}$, less extensive aggregation of the protein was observed, the decrease in enzymatic activity was much less marked, the overall extent of side-chain modification was reduced, and the majority of the observed amino acid side-chain modifications were detected on Met residues, with only low levels of modification seen at His and Tyr residues, though cross-links were detected between Arg33 and His48, and Tyr92 and Tyr115. Whether these species are intra- or inter-molecular linkages is discussed in more detail below. These data suggest that modification of each of the four Met residues present in the protein $(13,29,30,79)$, which were all modified to a moderate extent $(12-22 \%)$ does not markedly modulate enzyme activity. On the basis of these data, together with that for the ${ }^{1} \mathrm{O}_{2}$ system, we conclude that modification at the His and / or Tyr residues, and not Met residues, are the cause of the loss of enzymatic in RNAse. However, with the ${ }^{1} \mathrm{O}_{2}$ system, modification of the two active site His residues (His12 and His119), only occurs (in total) to 15\%, suggesting that modification to these residues alone cannot account for the near complete loss of enzyme activity. It would therefore appear that modification of multiple other residues, including one of the other His residues (His48), Tyr and possibly Pro residues may also contribute to the observed enzyme inactivation.

Common modifications were considered in the MS analysis [37], with a summary of the protein sequence, covered sequence and sites of modification / cross-linking given in Fig. 8 . There are some important caveats that need to be considered in the analysis of these data. The first of these is that there is some experimental uncertainty with regard to the levels of 
modification, as the applied method does not provide an absolute quantification, only ratios to the respective parent, and secondly, that the MS method as employed here relies on knowledge of the oxidation products, and particularly their molecular masses. This can result in divergent data between the extent of loss of parent amino acid (as determined, for example, by amino acid analysis), the levels of oxidation products detected by amino acid analysis after hydrolysis of the protein (which gives the total yield) and the MS data which provides exact positional and structural data, but only relative quantification. Furthermore, it is clear that with a number of amino acids (e.g. with His and Trp), our knowledge of the species formed is incomplete, and the material balance is poor, due to the plethora of possible oxidation products $[37,49]$.

While the extent of modification varied with the analysis method, the most oxidized amino acid with both oxidants was Met, with an average modification of $56 \%$ (MS data) after photo-oxidation with Rose Bengal (Fig. 3B). The main modifications detected were $+16 \mathrm{Da}$ ( $\sim 52$ $\%)$, and $+32 \mathrm{Da}(\sim 4 \%)$ consistent with formation of Met sulfoxide and sulfone (Fig. 3B). UPLC analysis gave $\sim 36 \%$ Met loss and $\sim 45 \%$ Met sulfoxide formation under the same conditions with ${ }^{1} \mathrm{O}_{2}$. The sulfoxide and sulfone are major products of Met oxidation, but other modifications are also known [17]. The conditions used to prepare samples for MS analysis may also convert Met to the sulfoxide, but in the current studies no significant Met oxidation was detected in the absence of the oxidant generating systems, suggesting that this is not a major factor under the conditions employed here (Supplementary Fig. 7).

For the AAPH system, Met oxidation was the major process detected, but with the ${ }^{1} \mathrm{O}_{2}$ system, $8 \%$ overall conversion of His to products was also detected, with this detected as both 
a $m / z+16$ Da and $m / z-10$ Da modifications (4 \% each). The first is consistent with the formation of 2-oxo-His, and the second with a ring-opened product that includes loss of a nitrogen. Much higher levels of modification ( $41 \%$ loss) were detected by amino acid analysis, consistent with the presence of additional products that were not detected in the MS analysis. The number of known modifications to His residues is significant [7-14], and most databases of posttranslational modifications do not include cross-linked products [37], thereby presenting significant challenges to obtaining a material balance between parent loss and product formation for this residue. The high level of modification of His is however consistent with the known high rate constant for reaction of ${ }^{1} \mathrm{O}_{2}$ with this amino acid [50].

The average extent of Tyr modification has been detected to be $\sim 5 \%$ by MS and $\sim 10 \%$ by amino acid analysis. The mass change detected by MS $(m / z+16)$ is consistent with the formation of DOPA, with this product also detected by the UPLC product analysis though at a low level $(1 \%)$, consistent with other products also being formed from this residue (e.g. crosslinks - see below). A $5 \%$ average modification of Pro (observed as a $m / z+16$ species; probably an alcohol) was also detected by MS; this modification was not detected in the UPLC amino acid analysis as this residue, being a secondary amine does not react rapidly with the OPA reagent used as the fluorescent tag to detect the amino acid residues.

With AAPH, the extent of the observed modifications was significantly lower. The MS methodology only showed significant average modification for Met (18\%, with this detected as the $m / z+16$ Da sulfoxide) with the extent of modification of His, Tyr and Pro all being $<1 \%$. With the amino acid analysis, $3 \%$ Met modification, and $26 \%$ Met sulfoxide formation was detected, together with $16 \%$ His and $5 \%$ Tyr modification. A small percentage $(0.16 \%)$ of di- 
Tyr formation was also detected, consistent with the presence of Tyr-based cross-links (see further below).

Mapping of the observed sites of modification on to the 3-dimensional structure of the protein shows that all of the residues at which oxidation occurs are at least partially surfaceaccessible; this is not surprising for a relatively small protein such as RNAse A, and particularly for one with a wide and deep active site cleft. These data are consistent with recent reports on the modification of surface-accessible His residues in other proteins, and cross-linking of these residues to small molecule nucleophiles [51,52]. Furthermore, the data obtained indicate significant damage to residues within this cleft, particularly with ${ }^{1} \mathrm{O}_{2}$, where marked oxidation of both His12, the proton acceptor during enzyme catalysis [1], and its neighboring residue Met13 is observed. The sulfur atoms of Met29 and Met30, which are also extensively oxidized, are relatively close $(<7 \AA)$, with the thioether function of Met30, $8 \AA$ distant from His12. The pattern of oxidation of all four Met residues $(13,29,30,79)$ is similar for the two oxidants, with the order being Met29 $>$ Met79 $>$ Met30 $>$ Met13, though the overall extent of modification is greater with ${ }^{1} \mathrm{O}_{2}$. This similarity may suggest that the accessibility of these residues (i.e. their local environment) is the most critical factor with regard to the extent of oxidation, as these two oxidants react with this residue via very different mechanisms.

The nature of the oxidation of His residues, detected with ${ }^{1} \mathrm{O}_{2}$, also appears to be environment dependent, with the oxidation products detected from His48, being mostly downstream (secondary) ring-opened products, whereas His12 in the active site [1,53], was detected primarily as a $m / z+16$ species, with this likely to be the hydroxylated species that is a precursor of the ring-opened products. Thus, a larger proportion of the His48 appears to be 
oxidized, and to a more severe extent, than His12. Mutation of His12 is known to be associated with a loss of enzymatic activity [54], but the degree of modification observed here is unlikely to explain, in its entirety, the near complete loss of activity. The extent of oxidation of His 105 and His 119 (the latter being the second catalytic His) [53], was much lower (2 \%) suggesting that these residues are less susceptible to modification. Oxidation of the Tyr residues also appears to be somewhat selective with four of the six present observed as modified species (Tyr35, Tyt73, Tyr92, Tyr97) with the last of these being most heavily modified ( 11\%) and in close spatial proximity to the heavily modified Met29/Met30 couple, though Tyr97 was not observed as a partner in any of the cross-linked species. Similarly of the four Pro residues present in the protein, Pro42 ( $22 \%$ ) was modified to a much higher extent than any other, with only Pro117 of the other Pro residues showing a low extent of alteration ( $2 \%)$.

The data obtained in this study, and also previously [55], indicates that RNAse is susceptible to inter-molecular protein crosslinking. Evidence has also been presented for RNARNAse cross-links arising from oxidation [56]. The MS data obtained here sheds light on the nature of these species, with four different cross-linked species detected with ${ }^{1} \mathrm{O}_{2}$ and two with ROO ${ }^{\bullet}$. These involve Tyr-Tyr, Tyr-Lys, His-Lys and His-Arg linkages for ${ }^{1} \mathrm{O}_{2}$, and Tyr-Tyr and HisArg for ROO ${ }^{\bullet}$. These cross-links appear to be both radical and ${ }^{1} \mathrm{O}_{2}$ dependent as evidenced by the SDS-gel data, with the generation of cross-linking by AAPH suppressed in the presence of the radical scavenger DMPO. In this latter case, the data are entirely consistent with formation of Tyr-derived phenoxyl radicals at Tyr92 and Tyr115, by ROO`, and subsequent reaction of these two radicals via the $3 / 5$ (ortho) positions [6] to give the observed species; this chemistry is consistent with the relatively long-lived (seconds to hours) nature of Tyr phenoxyl radicals on 
some proteins, though this is environment dependent $[6,57]$. These ring positions have been used to calculate distance distributions. Both residues are surface-exposed, consistent with a capacity to form cross-links, but remote from each other; the distance distributions determined from the solution NMR structure (PDB structure 2AAS) exhibit a median distance of $35.2 \AA$ and the shortest distance of $33.5 \AA$ (Fig. 7B). These long distances strongly suggest that this is an inter-molecular cross-link. The Tyr73-Tyr92 cross-link detected with ${ }^{1} \mathrm{O}_{2}$ also has a long median distance of $35.5 \AA$ (Supplementary Fig. 9), consistent with this being an inter-molecular species.

The Tyr92-Lys37 linkage detected on exposure of RNAse $A$ to ${ }^{1} \mathrm{O}_{2}$ has a much shorter median distance distribution of $\sim 9.72 \AA$ (Fig. 7B), with the shortest distance detected for one of the structures being $6.5 \AA$, assuming that reaction occurs between the amino nitrogen of the Lys side-chain and the $2 / 6$ positions of the Tyr residue. This mechanism is based on the known photochemistry of Tyr, and Tyr-Lys cross-linking [26,58], and involves the initial formation and subsequent reactions of an (endo)peroxide intermediate formed at the Tyr ring (Fig. 9). Based on the surface-accessibility and short distances between the respective $\mathrm{C}_{\alpha}$-atoms of the residues (< $10 \AA \AA$ distance, Fig. 7B) this is considered a candidate for both intra- and intermolecular cross-links, as median distance is shorter than that resulting in the maximum occurrence of zero-link crosslinking [59].

Cross-links involving His residues, have been also detected for both the $\mathrm{ROO}^{\bullet}$ and ${ }^{1} \mathrm{O}_{2}$ systems. For ROO ${ }^{\circ}$, evidence has been obtained for a cross-link between the His48 residue and Arg33. His48 appears, from the NMR structures, to be somewhat protected by the surrounding protein structure, but the length of $\operatorname{Arg} 33$ side-chain and its surface location are consistent with this being highly mobile, thereby allowing potential cross-link formation. Structural analysis of 
the family of NMR structures allows the median distance between this pair of residues to be determined as $10.8 \AA$ (Supplementary Fig. 9; with the shortest distance being $8.0 \AA ̊$ ), suggesting that this cross-link may be an intra-molecular bond. The exact mechanism by which this crosslink is formed is unclear. Literature data, and the amino acid analysis reported above, is inconsistent with direct $\mathrm{ROO}^{\circ}$ reaction with the Arg residue; hydrogen atom abstraction from C$\mathrm{H}$ bonds near to the positively-charged guanidinium group is likely to be disfavored. Therefore, initial oxidation of the His imidazole ring to give a histidinyl radical is the most likely initial step [8]. These species are known to react with $\mathrm{O}_{2}$ to give a peroxyl radical, with subsequent decay of this species yielding (via multiple steps) 2-oxo-histidine. The latter is likely to undergo nucleophilic attack by a nitrogen lone pair of the guanidine group to give an adduct species (cf. the chemistry described above and below for ${ }^{1} \mathrm{O}_{2}$ reactions with Tyr and His; see also [14]).

With ${ }^{1} \mathrm{O}_{2}$, a Lys1-His 48 cross-link was detected, with the median of the distance distribution between the highly mobile and surface accessible Lys1 residue and His48 being 28.4 $\AA$ (Fig. 7A). This large median distance is consistent with this being an inter-molecular linkage. A second His-containing cross-link was also detected for this oxidation system, with this involving His12, and either Lys37 and/or Arg33. The median distance distribution was $17.7 \AA$ (Supplementary Fig. 9; with the shortest distance being $14.5 \AA$ A) for the putative His12-Lys37 cross-link, and (11.03 $\AA$, with the shortest distance $7.75 \AA ̊$ ) for a His12-Arg33 cross-link (Fig. 7A). The shorter distance of the latter makes this the more likely candidate, with this being an intramolecular cross-link. A linkage involving an Arg residue is plausible, and may occur by an analogous mechanism to that reported previously for cross-linking of Lys residues with His, which involves initial formation of endoperoxide at the His ring, and subsequent nucleophilic 
attack by a nitrogen lone pair from the Lys or Arg residue [9,14] (Fig. 9) For both Lys and Arg, the $\mathrm{pK}_{\mathrm{a}}$ value of the side-chain nitrogen in bulk solution (Lys: 10.5, Arg 12.5) are high, making a nucleophilic attack of the amine lone pair less favorable, though such species have been detected previously with Lys residues at neutral $\mathrm{pH}$, and the local environment of the residue may markedly alter these $\mathrm{pK}_{\mathrm{a}}$ values making reaction more likely. His 12 is known to be critical for the activity of the enzyme, together with His119, which act as a proton acceptor and proton donor, respectively, during the catalytic cycle $[1,54]$. Previous studies have shown that mutation of these amino acids results in a loss of activity [54]. No evidence was found for HisHis cross-linking (involving $m / z+14$ or +16 species) despite previous evidence for the formation of these species on His oxidation (e.g. $[9,14])$. The formation of the observed cross-links, and particularly those involving His12, may contribute, together with direct modification of the catalytic site side-chains, to the observed loss of enzyme activity after exposure to ${ }^{1} \mathrm{O}_{2}$. This conclusion is supported by previous literature data that indicates that oligomerization of RNAse A affects enzyme function [5].

Oxidative modification and cross-linking of RNAses which result in a loss of enzymatic activity may be of pathophysiological relevance in conditions linked to oxidative stress. Bovine RNAse has substantial sequence homology to the human RNAse A superfamily (RNAse's 1-8) [60], with, for example, $82 \%$ to human RNAse 1 (mainly found in pancreas), $66 \%$ to RNAse 4 (mainly found in liver), and $51 \%$ to RNAse 8 (mainly placenta), with a considerable proportion of the divergence between the bovine and human forms arising from chain extensions at the $\mathrm{N}$ terminus (Supplementary Fig. 10). The physiological purpose of the RNAse family is not completely understood, but there is considerable evidence that this family plays a key role in 
the innate immune system and has direct antiviral activity as might be expected from its enzymatic activity $[60,61]$. Evidence has been presented for an association between diabetes and oxidative stress [62], with elevated levels of ${ }^{1} \mathrm{O}_{2}$-specific fatty oxidation products detected in the early stages of Type 2 disease [63], consistent with a role for this reactive intermediate. Moreover, an increased risk for common viral infections has been reported for people with Type 1 and 2 diabetes [64], which may be associated with decreased RNAse activity as a result of oxidative damage to the enzyme. Indeed, lower plasma RNAse activity has been found in a group with Type 1 diabetes compared to controls [65]. An interplay between the increased susceptibility to infections in diabetes and RNAse activity has been hypothesized previously [65], and the oxidative modifications and the cross-links reported here (as well as those potentially arising from glucose-induced Maillard reactions [55]), may contribute to the observed functional and pathophysiological phenomena.

Taken together, our findings describe functional and structural changes of RNAse A resulting from oxidation by two commonly encountered oxidation systems, $\mathrm{ROO}^{\bullet}$ and ${ }^{1} \mathrm{O}_{2}$. The extent and pattern of damage is markedly different between these species, with the latter being considerably more damaging. Both oxidants induced (irreversible) multimer formation and a loss of activity, but this was considerably less marked with ROO ${ }^{\circ}$. Identification, quantification and mapping of the modifications induced by the oxidants indicates that although Met residues are very prone to oxidation (to give methionine sulfoxide), the oxidation of these residues is not primarily responsible for the loss of activity. Damage to His and Tyr residues, both as a result of direct conversion to oxidized products, and also via cross-link formation, appears to the primary cause of activity loss. The oxidative damage induced by both 
oxidants is not equally distributed with some residues showing much greater levels of modification than others, both in terms of the extent of oxidation and severity of the damage. Thus, evidence has been detected for products (e.g at His48) that are consistent with multiple sequential reactions and destruction of the imidazole ring. In other cases, damage is limited to mono-oxygenation (i.e. $m / z+16$ species). Multiple cross-links, assigned to both inter- and intramolecular species have also been observed, including (well established) Tyr-Tyr cross-linked species, and less well established His-Lys, His-Arg and Tyr-Lys linkages, with some of these involving the active site His12 residue. Together these modifications may contribute to the observed loss of activity. As the RNAse family shows a high degree of homology, the loss of activity and structural changes induced by ${ }^{1} \mathrm{O}_{2}$ oxidation may be a common process within this enzyme family, and possibly contribute to the increased risk of viral infections in people with diabetes.

\section{Acknowledgements}

The authors are grateful for financial support from the Novo Nordisk Foundation (grant: NNF130C0004294 to MJD). The Orbitrap mass spectrometers used in this study were granted by the Danish Council for Independent Research | Natural Sciences (grant number 11-106246) and the Velux Foundation. The Danish Research Foundation, Nordic Bioscience A/S and Technical University of Denmark are acknowledged for a co-funded PhD scholarship to MM. 


\section{References}

[1] Raines, R. T. Ribonuclease A. Chem. Rev. 98 (1998) 1045-1066.

[2] Davies, M. J. Protein oxidation and peroxidation. Biochem. J. 473 (2016) 805-825

[3] Ehrenshaft, M.; Deterding, L. J.; Mason, R. P. Tripping up trp: Modification of protein tryptophan residues by reactive oxygen species, modes of detection, and biological consequences. Free Radic. Biol. Med. 89 (2015) 220-228.

[4] Lasch, P.; Petras, T.; Ullrich, O.; Backmann, J.; Naumann, D.; Grune, T. Hydrogen peroxideinduced structural alterations of rnase a. J. Biol. Chem. 276 (2001) 9492-9502.

[5] Libonati, M.; Gotte, G. Oligomerization of bovine ribonuclease a: Structural and functional features of its multimers. Biochem. J. 380 (2004) 311-327.

[6] Houee-Levin, C.; Bobrowski, K.; Horakova, L.; Karademir, B.; Schoneich, C.; Davies, M. J.;

Spickett, C. M. Exploring oxidative modifications of tyrosine: An update on mechanisms of formation, advances in analysis and biological consequences. Free Radic. Res. 49 (2015) 347-373.

[7] Lewisch, S. A.; Levine, R. L. Determination of 2-oxohistidine by amino acid analysis. Anal. Biochem. 231 (1995) 440-446.

[8] Schoneich, C. Mechanisms of metal-catalyzed oxidation of histidine to 2-oxo-histidine in peptides and proteins. J. Pharm. Biomed. Anal. 21 (2000) 1093-1097.

[9] Agon, V. V.; Bubb, W. A.; Wright, A.; Hawkins, C. L.; Davies, M. J. Sensitizer-mediated photooxidation of histidine residues: Evidence for the formation of reactive side-chain peroxides. Free Radic. Biol. Med. 40 (2006) 698-710.

[10] Shen, H.-R.; Spikes, J. D.; Smith, C. J.; Kopecek, J. Photodynamic cross-linking of proteins IV. Nature of the His-His bond(s) formed in the rose bengal-photosensitized cross-linking of $\mathrm{N}$-benzoyl-Lhistidine. J. Photochem. Photobiol. A: Chem. 130 (2000) 1-6. 
[11] Shen, H. R.; Spikes, J. D.; Kopecekova, P.; Kopecek, J. Photodynamic crosslinking of proteins. I. Model studies using histidine- and lysine-containing n-(2-hydroxypropyl)methacrylamide copolymers. J. Photochem. Photobiol. B 34 (1996) 203-210.

[12] Tomita, M.; Irie, M.; Ukita, T. Sensitized photooxidation of histidine and its derivatives. Products and mechanism of the reaction. Biochemistry 8 (1969) 5149-5160.

[13] Liu, M.; Zhang, Z.; Cheetham, J.; Ren, D.; Zhou, Z. S. Discovery and characterization of a photooxidative histidine-histidine cross-link in IgG1 antibody utilizing ${ }^{18} \mathrm{O}$-labeling and mass spectrometry. Anal. Chem. 86 (2014) 4940-4948.

[14] Xu, C. F.; Chen, Y.; Yi, L.; Brantley, T.; Stanley, B.; Sosic, Z.; Zang, L. Discovery and characterization of histidine oxidation initiated cross-links in an IgG1 monoclonal antibody. Anal. Chem. 89 (2017) 7915-7923.

[15] Schoneich, C. Methionine oxidation by reactive oxygen species: Reaction mechanisms and relevance to Alzheimer's disease. Biochim. Biophys. Acta 1703 (2005) 111-119.

[16] Schoneich, C.; Aced, A.; Asmus, K. D. Mechanism of oxidation of aliphatic thioethers to sulfoxides by hydroxyl radicals - the importance of molecular oxygen. J. Am. Chem. Soc. 115 (1993) 11376-11383.

[17] Barata-Vallejo, S.; Ferreri, C.; Zhang, T.; Permentier, H.; Bischoff, R.; Bobrowski, K.; Chatgilialoglu, C. Radiation chemical studies of Gly-Met-Gly in aqueous solution. Free Radic. Res. 50 (2016) S24-S39.

[18] Gajewski, E.; Dizdaroglu, M.; Krutzsch, H. C.; Simic, M. G. OH radical-induced crosslinks of methionine peptides. Int. J. Radiat. Biol. 46 (1984) 47-55.

[19] Ronsein, G. E.; Winterbourn, C. C.; Di Mascio, P.; Kettle, A. J. Cross-linking methionine and amine residues with reactive halogen species. Free Radic. Biol. Med. 70 (2014) 278-287. 
[20] Bhave, G.; Cummings, C. F.; Vanacore, R. M.; Kumagai-Cresse, C.; Ero-Tolliver, I. A.; Rafi, M.;

Kang, J. S.; Pedchenko, V.; Fessler, L. I.; Fessler, J. H.; Hudson, B. G. Peroxidasin forms sulfilimine chemical bonds using hypohalous acids in tissue genesis. Nat. Chem. Biol. 8 (2012) 784-790.

[21] Halliwell, B.; Gutteridge, J. M. C. Free radicals in biology \& medicine. Oxford: Oxford University Press; 2015.

[22] Porter, N. A.; Wagner, C. R. Phospholipid autoxidation. Adv. Free Radic. Biol. Med. 2 (1986) 283323.

[23] Davies, M. J. Singlet oxygen-mediated damage to proteins and its consequences. Biochem. Biophys. Res. Commun. 305 (2003) 761-770.

[24] Pattison, D. I.; Rahmanto, A. S.; Davies, M. J. Photo-oxidation of proteins. Photochem. Photobiol. Sci 11 (2012) 38-53.

[25] Leinisch, F.; Mariotti, M.; Rykaer, M.; Lopez-Alarcon, C.; Hagglund, P.; Davies, M. J. Peroxyl radical- and photo-oxidation of glucose 6-phosphate dehydrogenase generates cross-links and functional changes via oxidation of tyrosine and tryptophan residues. Free Radic. Biol. Med. 112 (2017) $240-252$.

[26] Wright, A.; Bubb, W. A.; Hawkins, C. L.; Davies, M. J. Singlet oxygen-mediated protein oxidation: Evidence for the formation of reactive side-chain peroxides on tyrosine residues. Photochem. Photobiol. 76 (2002) 35-46.

[27] Pitre, S. P.; McTiernan, C. D.; Vine, W.; DiPucchio, R.; Grenier, M.; Scaiano, J. C. Visible-light actinometry and intermittent illumination as convenient tools to study $\mathrm{Ru}(\mathrm{bpy}) 3 \mathrm{Cl} 2$ mediated photoredox transformations. Sci. Rep. 5 (2015) 16397.

[28] Arenas, A.; Lopez-Alarcon, C.; Kogan, M.; Lissi, E.; Davies, M. J.; Silva, E. Chemical modification of lysozyme, glucose 6-phosphate dehydrogenase, and bovine eye lens proteins induced by peroxyl radicals: Role of oxidizable amino acid residues. Chem. Res. Toxicol. 26 (2013) 67-77. 
[29] Werber, J.; Wang, Y. J.; Milligan, M.; Li, X.; Ji, J. A. Analysis of 2,2'-azobis (2-amidinopropane) dihydrochloride degradation and hydrolysis in aqueous solutions. J. Pharm. Sci. 100 (2011) 3307-3315. [30] Niki, E. Free radical initiators as source of water- or lipid-soluble peroxyl radicals. Meth. Enzymol. 186 (1990) 100-108.

[31] Candiano, G.; Bruschi, M.; Musante, L.; Santucci, L.; Ghiggeri, G. M.; Carnemolla, B.; Orecchia, P.; Zardi, L.; Righetti, P. G. Blue silver: A very sensitive colloidal Coomassie G-250 staining for proteome analysis. Electrophoresis 25 (2004) 1327-1333.

[32] Kunitz, M. A. Spectrophotometric method for the measurement of ribonuclease activity. J. Biol. Chem. 164 (1946) 563-568.

[33] Hawkins, C. L.; Morgan, P. E.; Davies, M. J. Quantification of protein modification by oxidants. Free Radic. Biol. Med. 46 (2009) 965-988.

[34] Wisniewski, J. R.; Zougman, A.; Nagaraj, N.; Mann, M. Universal sample preparation method for proteome analysis. Nat. Meth. 6 (2009) 359-U360.

[35] Cox, J.; Mann, M. Maxquant enables high peptide identification rates, individualized p.p.b.-range mass accuracies and proteome-wide protein quantification. Nat. Biotechnol. 26 (2008) 1367-1372.

[36] Cox, J.; Neuhauser, N.; Michalski, A.; Scheltema, R. A.; Olsen, J. V.; Mann, M. Andromeda: A peptide search engine integrated into the maxquant environment. J. Proteome Res. 10 (2011) 17941805.

[37] Bachi, A.; Dalle-Donne, I.; Scaloni, A. Redox proteomics: Chemical principles, methodological approaches and biological/biomedical promises. Chem. Rev. 113 (2013) 596-698.

[38] Rykaer, M.; Svensson, B.; Davies, M. J.; Hagglund, P. Unrestricted mass spectrometric data analysis for identification, localization and quantification of oxidative protein modifications. J. Proteome Res. 16 (2017) 3978-3988. 
[39] MacLean, B.; Tomazela, D. M.; Shulman, N.; Chambers, M.; Finney, G. L.; Frewen, B.; Kern, R.;

Tabb, D. L.; Liebler, D. C.; MacCoss, M. J. Skyline: An open source document editor for creating and analyzing targeted proteomics experiments. Bioinformatics 26 (2010) 966-968.

[40] Mariotti, M.; Leinisch, F.; Leeming, D. J.; Svensson, B.; Davies, M. J.; Hägglund, P. Massspectrometry-based identification of cross-links in proteins exposed to photo-oxidation and peroxyl radicals using 180 labeling and optimized tandem mass spectrometry fragmentation. J. Proteome Res. in press DOI: 10.1021/acs.jproteome.7b00881 (2018)

[41] Koradi, R.; Billeter, M.; Wuthrich, K. Molmol: A program for display and analysis of macromolecular structures. J. Mol. Graph. 14 (1996) 51-55.

[42] Octave, G.: Top. Available at: Https://www.Gnu.Org/software/octave/doc/interpreter/. (accessed: 4th december 2017).

[43] Toiron, C.; Gonzalez, C.; Bruix, M.; Rico, M. Three-dimensional structure of the complexes of ribonuclease a with $2^{\prime}, 5^{\prime}-$ cpa and 3',5'-d(cpa) in aqueous solution, as obtained by $\mathrm{nmr}$ and restrained molecular dynamics. Protein Sci. 5 (1996) 1633-1647.

[44] Rath, A.; Glibowicka, M.; Nadeau, V. G.; Chen, G.; Deber, C. M. Detergent binding explains anomalous sds-page migration of membrane proteins. Proc. Natl. Acad. Sci. U S A 106 (2009) 1760-1765. [45] Davies, M. J. Detection and characterisation of radicals using electron paramagnetic resonance (epr) spin trapping and related methods. Methods 109 (2016) 21-30.

[46] Redmond, R. W.; Gamlin, J. N. A compilation of singlet oxygen yields from biologically relevant molecules. Photochem. Photobiol. 70 (1999) 391-475.

[47] Alarcon, E.; Edwards, A. M.; Aspee, A.; Borsarelli, C. D.; Lissi, E. A. Photophysics and photochemistry of rose bengal bound to human serum albumin. Photochem. Photobiol. Sci. 8 (2009) 933-943. 
[48] Silvester, J. A.; Timmins, G. S.; Davies, M. J. Photodynamically-generated bovine serum albumin radicals: Evidence for damage transfer and oxidation at cysteine and tryptophan residues. Free Radic. Biol. Med. 24 (1998) 754-766.

[49] Zhang, L.; Yadav, S.; Wang, Y. J.; Mozziconacci, O.; Schoneich, C. Dual effect of histidine on polysorbate 20 stability: Mechanistic studies. Pharm. Res. 35 (2018)

[50] Wilkinson, F.; Helman, W. P.; Ross, A. B. Rate constants for the decay and reactions of the lowest electronically excited state of molecular oxygen in solution. An expanded and revised compilation. J. Phys. Chem. Ref. Data 24 (1995) 663-1021.

[51] Lei, M.; Carcelen, T.; Walters, B. T.; Zamiri, C.; Quan, C.; Hu, Y.; Nishihara, J.; Yip, H.; Woon, N.; Zhang, T.; Kao, Y. H.; Schoneich, C. Structure-based correlation of light-induced histidine reactivity in a model protein. Anal. Chem. 89 (2017) 7225-7231.

[52] Lei, M.; Quan, C.; Wang, Y. J.; Kao, Y. H.; Schoneich, C. Light-induced covalent buffer adducts to histidine in a model protein. Pharm. Res. 35 (2018) 67.

[53] Santoro, J.; Gonzalez, C.; Bruix, M.; Neira, J. L.; Nieto, J. L.; Herranz, J.; Rico, M. High-resolution 3dimensional structure of ribonuclease-A in solution by nuclear-magnetic-resonance spectroscopy. J. Mol. Biol. 229 (1993) 722-734.

[54] Delcardayre, S. B.; Ribo, M.; Yokel, E. M.; Quirk, D. J.; Rutter, W. J.; Raines, R. T. Engineering ribonuclease-A - production, purification and characterization of wild-type enzyme and mutants at Gln11. Protein Eng. 8 (1995) 261-273.

[55] Eble, A. S.; Thorpe, S. R.; Baynes, J. W. Non-enzymatic glucosylation and glucose-dependent cross-linking of protein. J. Biol. Chem. 258 (1983) 9406-9412.

[56] Kramer, K.; Sachsenberg, T.; Beckmann, B. M.; Qamar, S.; Boon, K. L.; Hentze, M. W.; Kohlbacher, O.; Urlaub, H. Photo-cross-linking and high-resolution mass spectrometry for assignment of RNA-binding sites in RNA-binding proteins. Nat. Meth. 11 (2014) 1064-1070. 
[57] Stubbe, J.-A. Radicals with a controlled lifestyle. Chem. Comm. 20 (2003) 2511-2513.

[58] Winterbourn, C. C.; Parsons-Mair, H. N.; Gebicki, S.; Gebicki, J. M.; Davies, M. J. Requirements for superoxide-dependent tyrosine hydroperoxide formation in peptides. Biochem. J. 381 (2004) 241248.

[59] Leitner, A.; Joachimiak, L. A.; Unverdorben, P.; Walzthoeni, T.; Frydman, J.; Forster, F.;

Aebersold, R. Chemical cross-linking/mass spectrometry targeting acidic residues in proteins and protein complexes. Proc. Natl. Acad. Sci. U S A 111 (2014) 9455-9460.

[60] Koczera, P.; Martin, L.; Marx, G.; Schuerholz, T. The ribonuclease A superfamily in humans: Canonical rnases as the buttress of innate immunity. Int. J. Mol. Sci. 17 (2016)

[61] Ilinskaya, O. N.; Shah Mahmud, R. Ribonucleases as antiviral agents. Mol. Biol. 48 (2014) 615623.

[62] Brownlee, M. The pathobiology of diabetic complications: A unifying mechanism. Diabetes 54 (2005) 1615-1625.

[63] Murotomi, K.; Umeno, A.; Yasunaga, M.; Shichiri, M.; Ishida, N.; Abe, H.; Yoshida, Y.; Nakajima, Y. Switching from singlet-oxygen-mediated oxidation to free-radical-mediated oxidation in the pathogenesis of type 2 diabetes in model mouse. Free Radic. Res. 49 (2015) 133-138.

[64] Muller, L. M. A. J.; Gorter, K. J.; Hak, E.; Goudzwaard, W. L.; Schellevis, F. G.; Hoepelman, A. I. M.; Rutten, G. E. H. M. Increased risk of common infections in patients with type 1 and type 2 diabetes mellitus. Clin. Infect. Dis. 41 (2005) 281-288.

[65] Kocic, G.; Bjelakovic, G.; Saranac, L.; Zivic, S.; Jevtovic, T.; Sokolovic, D.; Pavlovic, D.; Pavlovic, R.; Kocic, R. Possible impact of plasma RNAse activity on immune dysfunction in juvenile diabetes mellitus. Pediatr. Diabetes 6 (2005) 155-160.

[66] Aeschbach, R.; Amado, R.; Neukom, H. Formation of dityrosine cross-links in proteins by oxidation of tyrosine residues. Biochim. Biophys. Acta 439 (1976) 292-301. 
[67] Boguta, G.; Dancewicz, A. M. Radiolytic and enzymatic dimerization of tyrosyl residues in insulin, ribonuclease, papain and collagen. Int. J. Radiat. Biol. 43 (1983) 249-265.

[68] Moller, M. N.; Hatch, D. M.; Kim, H. Y.; Porter, N. A. Superoxide reaction with tyrosyl radicals generates para-hydroperoxy and para-hydroxy derivatives of tyrosine. J. Am. Chem. Soc. 134 (2012) 16773-16780.

Fig. 1. Panel A) SDS-PAGE analysis of control and treated RNAse A samples ( $30 \mu \mathrm{M}$, in phosphate buffer, $\mathrm{pH}$ 7.4) using 4 - 12\% Bis-Tris acrylamide gels under reducing conditions (for further conditions, see Materials and methods). CTRL: native RNAse; +AAPH: RNAse exposed to $10 \mathrm{mM} \mathrm{AAPH}$ for $90 \mathrm{~min}$ at $40^{\circ} \mathrm{C}$; hv: RNAse exposed to visible light for $90 \mathrm{~min}$ in the presence of $\mathrm{O}_{2}$ in $70 \% \mathrm{D}_{2} \mathrm{O}$, but with no Rose Bengal (RB); RB: RNAse incubated with $10 \mu \mathrm{M}$ Rose Bengal for 90 min in the presence of $\mathrm{O}_{2}$ in $70 \% \mathrm{D}_{2} \mathrm{O}$, but in the absence of light; RB hv: - RNAse exposed to $10 \mu \mathrm{M}$ Rose Bengal in the presence of light for $90 \mathrm{~min}$ in the presence of $\mathrm{O}_{2}$ in $70 \% \mathrm{D}_{2} \mathrm{O} . \mathrm{M}=$ molecular mass markers. Panel B): As panel A), with either control RNAse A or complete reaction systems, with increasing reaction, or light exposure time as indicated on the horizontal. Panel C): Densitometric analysis of representative SDS-PAGE gels from the RB oxidation system at different time points as indicated on the panel. Panel D: Densitometric analysis of representative SDS-PAGE gels from the $\mathrm{ROO}^{\bullet}$ oxidation at the indicated time points. 
Fig. 2. Enzymatic activity (Kunitz units) of control RNAse $A$, and RNAse exposed to ${ }^{1} \mathrm{O}_{2}$ or ROO'. Activity was determined as indicated in the Materials and methods. Panel A: Representative plot of time dependent changes in RNA absorbance at $300 \mathrm{~nm}$ for control and oxidant treated RNAse A. Panel B: Quantification of Kunitz units of activity for control samples of RNAse, RNAse treated with $\mathrm{ROO}^{\circ}$ and ${ }^{1} \mathrm{O}_{2}$, and RNA samples treated with AAPH (bar labelled "AAPH") or Rose Bengal, $\mathrm{O}_{2}$ and light (bar labelled "RB") in the absence of RNAse.

Fig. 3. Extent of modification of different amino acid side chains in RNAse. Panel A): ROO ${ }^{\bullet}$ mediated oxidation, as monitored by MS. Panel B): ${ }^{1} \mathrm{O}_{2}$-mediated oxidation, as monitored by MS. Panel C): Quantification, as percentages, of specific oxidation products compared to total content of parent amino acid as determined by UPLC with fluorescence detection. See main text for details. Colored boxes indicate mass changes in Da examined using the MS approach as indicated in the panels. Based on the MS results, Met is the most readily oxidized of the analyzed amino acids, with the primary product being a +16 Da species assigned to the sulfoxide. Using the ${ }^{1} \mathrm{O}_{2}$ system, evidence for $\mathrm{His}(\mathrm{H}), \operatorname{Tyr}(\mathrm{Y})$ and Pro $(\mathrm{P})$ modifications were also detected, though to a lesser extent, with +32 Da product(s) detected for Met (assigned to the sulfone) and a-10 Da species for His (aspartylurea; see main text for further details). With the UPLC analysis, low of DOPA were detected with the ROO ${ }^{\bullet}$ system, and for the ${ }^{1} \mathrm{O}_{2}$ system low levels of diTyr. In both cases the majority of the Tyr residues determined to be lost could not be accounted for as known products using the analytical methods employed. 
Fig. 4. MS/MS spectra of identified cross-linked peptides. A) quadruply charged di-Tyr crosslinked peptide (NGQTNCY ${ }^{73}$ QSYSTMSITDCR) (ETGSSKY ${ }^{92}$ PNCAYK), with precursor $m / z$ of 947.646; B) triply charged Lys-Tyr cross-linked peptide (SRNLTK ${ }^{37}$ DR) (ETGSSKY ${ }^{92}$ PNCAYK), with precursor m/z of 836.399; C) quintuply (+5) charged Arg-His cross-linked peptide (SR ${ }^{33}$ NLTKDR) (RQH ${ }^{12}$ MDSSTSAASSSNYCNQMMK), with precursor $m / z$ of 708.714 . Blue $y$ and $b$ fragments correspond to the $\alpha$ (longer) peptide, while red $y$ and $b$ fragments correspond to the $\beta$ (shorter) peptide. In panel C), - Indicates the presence of an oxidized Met residue (+ $16 \mathrm{Da})$.

Fig. 5. Mapping of oxidation and cross-links induced by $\mathrm{ROO}^{\bullet}$ to the RNAse sequence and structure. In panel a), the positions of the catalytic dyad and observed cross-links are indicated. In panel b), the extent of modification at individual amino acids as determined by MS is presented relative to the RNAse protein sequence. Vertical axis indicates the \% modification of Met $(\mathrm{M})$, His $(\mathrm{H}), \operatorname{Tyr}(\mathrm{Y})$ and Pro $(\mathrm{P})$ residues at specific sites, calculated as outlined in Materials and methods from technical replicates, with the horizontal axis indicating the amino acid sequence and numbering. Panel c) shows a rendering of the Met, Tyr His and Pro residues on the 3-dimensional structure of the protein generated using the multiple structures provided in PDB structure 2AAS. Each of the oxidized side-chains appears to be surface accessible, but the lesser oxidized Met13 (M13) residues is somewhat protected by a loop. The horizontal axes in a) and b) refer to the amino acid numbering of the residues in the mature protein sequence.

Fig. 6. Mapping of oxidation and cross-links induced by ${ }^{1} \mathrm{O}_{2}$ to the RNAse sequence and structure. In panel a), the positions of the catalytic dyad and observed cross-links are indicated. 
In panel b), the extent of modification at individual amino acids as determined by MS is presented relative to the RNAse protein sequence, as described in the legend to Figure 5. While some residues appear virtually unmodified residues, other residues are highly oxidized, others engage in both cross-linking and oxidation, such as His-12 (H12), which is part of the catalytic site. Panel c) shows a rendering of the Met, Tyr His and Pro residues on the 3-dimensional structure of the protein generated using the multiple structures provided in PDB structure 2AAS. The residues are surface-accessible and somewhat grouped around M29/30 and H12. See main text for details. The horizontal axes in a) and b) refer to the amino acid numbering of the residues in the mature protein sequence.

Fig. 7. Rendering of the two discovered Tyr (Panel A) and His (Panel B) cross links with distance distributions using the multiple structures for RNAse reported in PDB structure 2AAS. In both cases, distances short enough for intra-molecular cross-linking as well as long enough for intermolecular cross-linking have been found. The species shown are His-Arg, His-Lys (both ${ }^{1} \mathrm{O}_{2}$ ) and Tyr-Tyr (ROO') and Lys-Tyr $\left({ }^{1} \mathrm{O}_{2}\right)$. The H12-R33 crosslink affects the active site and is short enough for intramolecular cross-linking.

Fig. 8. Summary of primary structure of RNAse, the sequence coverage detected by MS, and the detected sites of oxidation and cross-linking. Numbering of the amino acids is with respect to the mature protein with the signal peptide (amino acids 1-26 in the gene sequence removed). The sequence detected by MS is indicated in green text, and corresponds to $87 \%$ of the mature protein. All four of the Cys residues are present in the form of disulfides (Cys26-Cys84; Cys58- 
Cys110). Sites of oxidation $[Y(m / z+16), H(m / z+5, m / z-10, m / z+16, m / z-22, m / z-23, m / z+56)$,

$\mathrm{M}(m / z+16, m / z+32), \mathrm{P}(m / z+16)]$ with a detected extent of modification of $>5 \%$ are indicated in red text, and the residues involved in cross-link formation are indicated with blue text (K37-Y92, Y92-Y115, K1-H48, H12-R33). The two His residues that form the active site dyad (His12, His119) are highlighted in yellow.

Fig. 9. Proposed mechanisms of cross-link formation on oxidized RNAse A. Di-Tyr formation in proposed to occur via radical mediated oxidation, and subsequent recombination of two Tyrderived phenoxyl radicals with carbon-carbon coupling as reported previously $[66,67]$. For TyrLys formation with ${ }^{1} \mathrm{O}_{2}$, a Tyr-derived peroxide has been reported as an intermediate [26], which can react further with nucleophiles such as amines $[58,68]$. The proposed His-Arg mechanism is similar, but the His-peroxide intermediate $[9,12]$ further reacts an alcohol which then reacts with nucleophiles such as amines [9]. 
A)

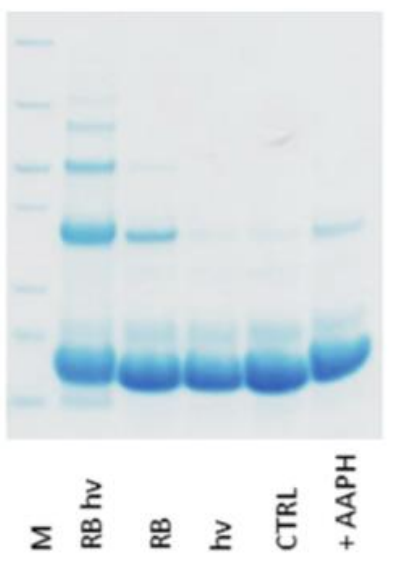

RNAse

C)

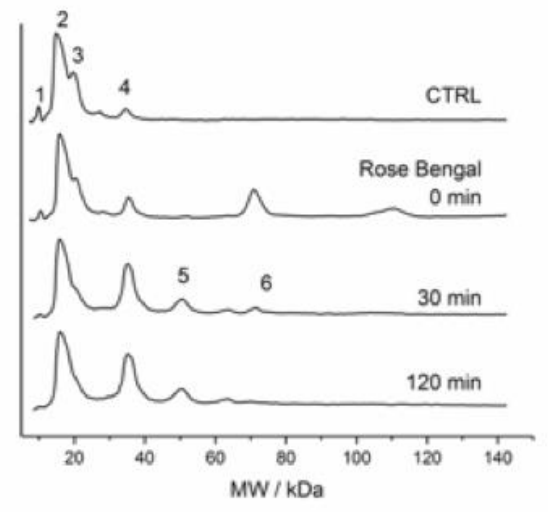

B)

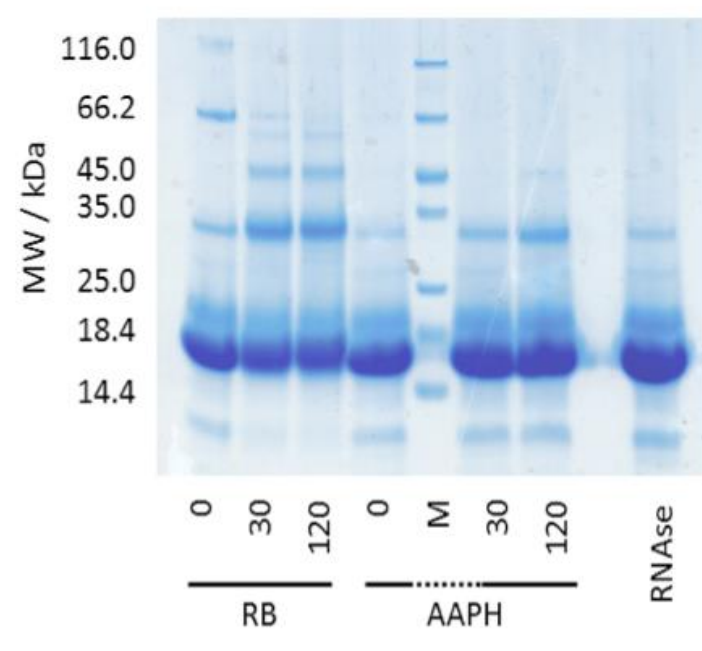

D)

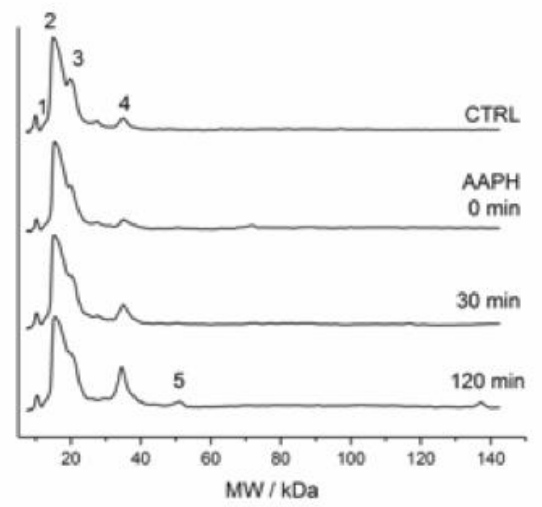




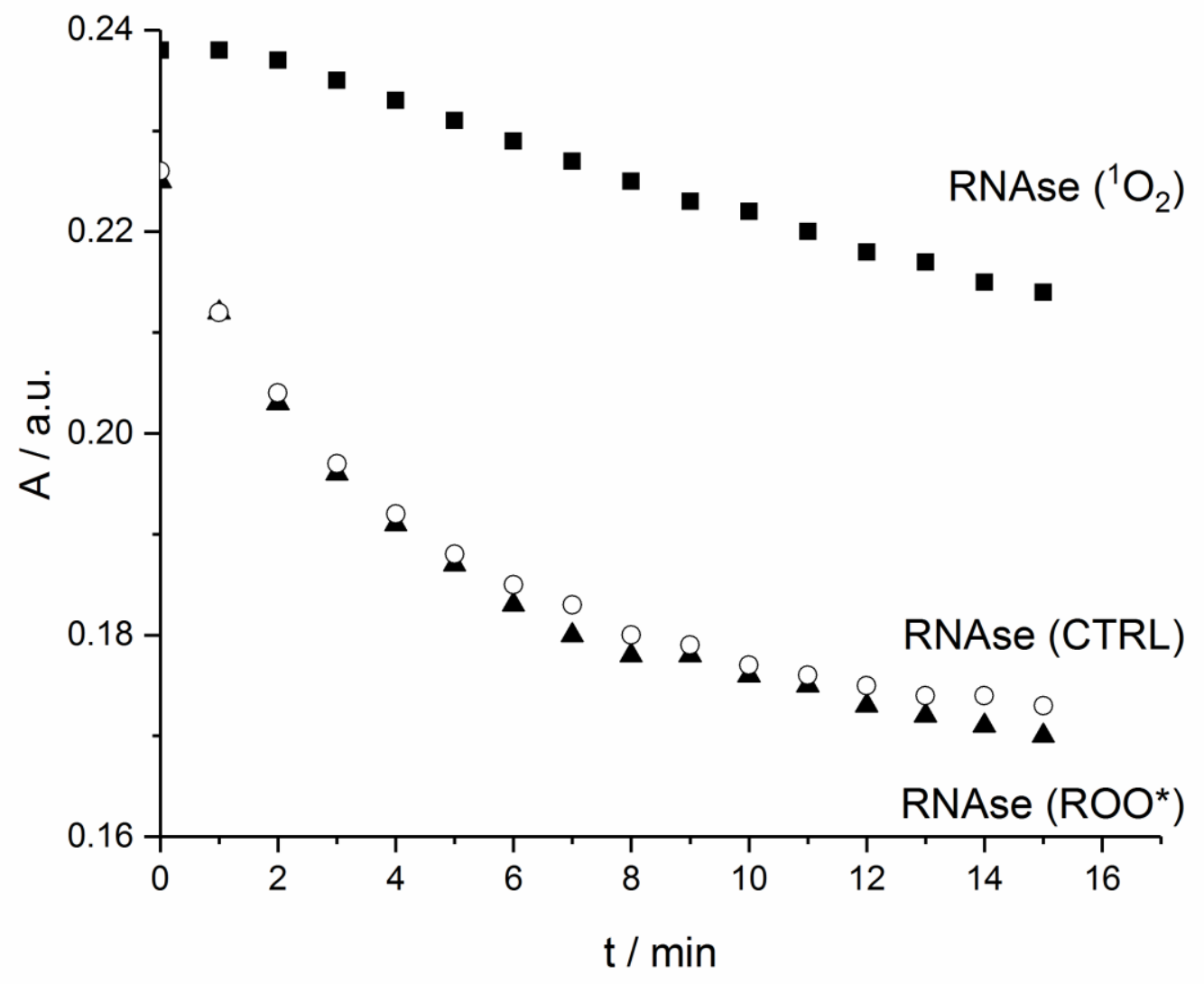




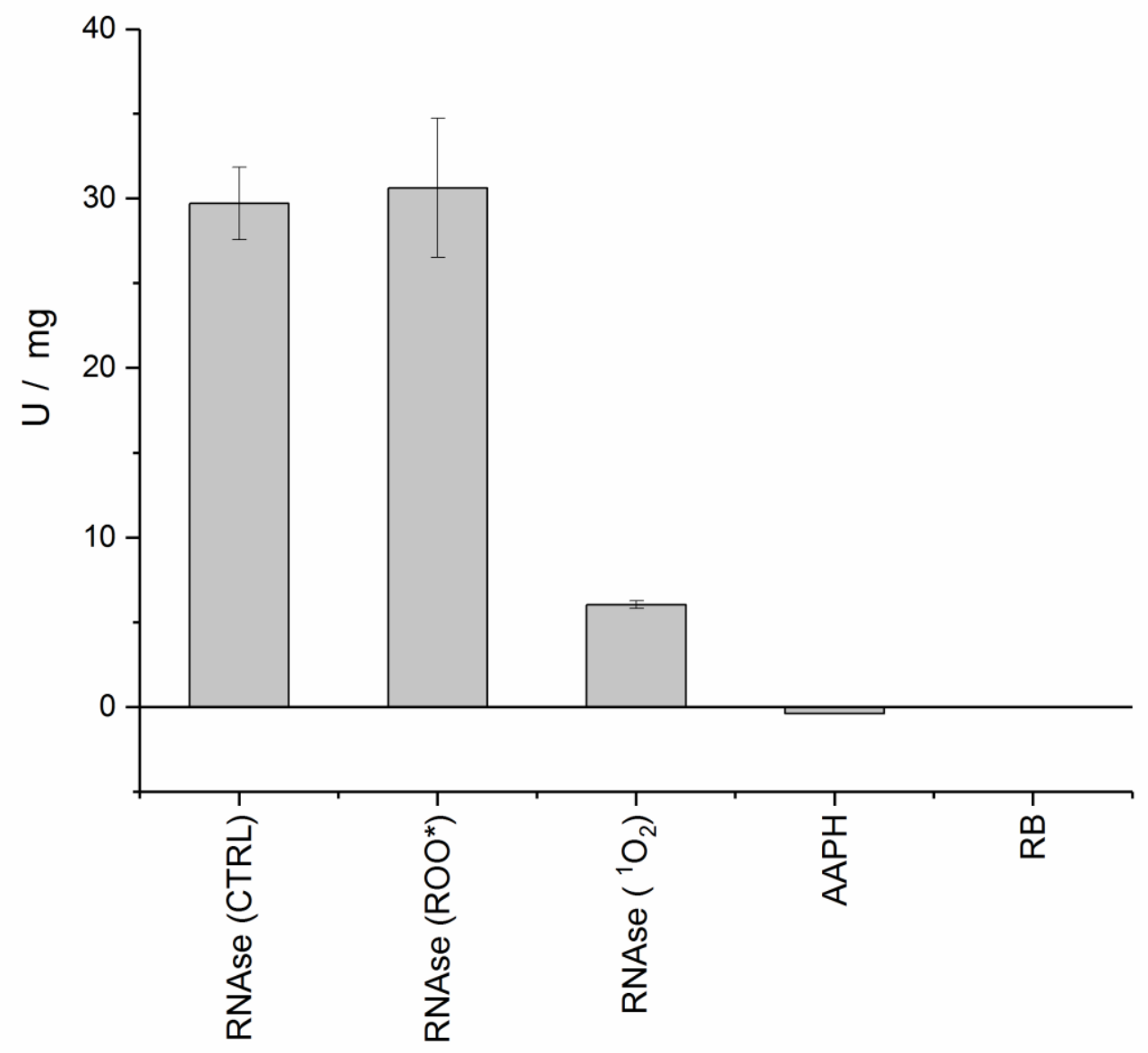




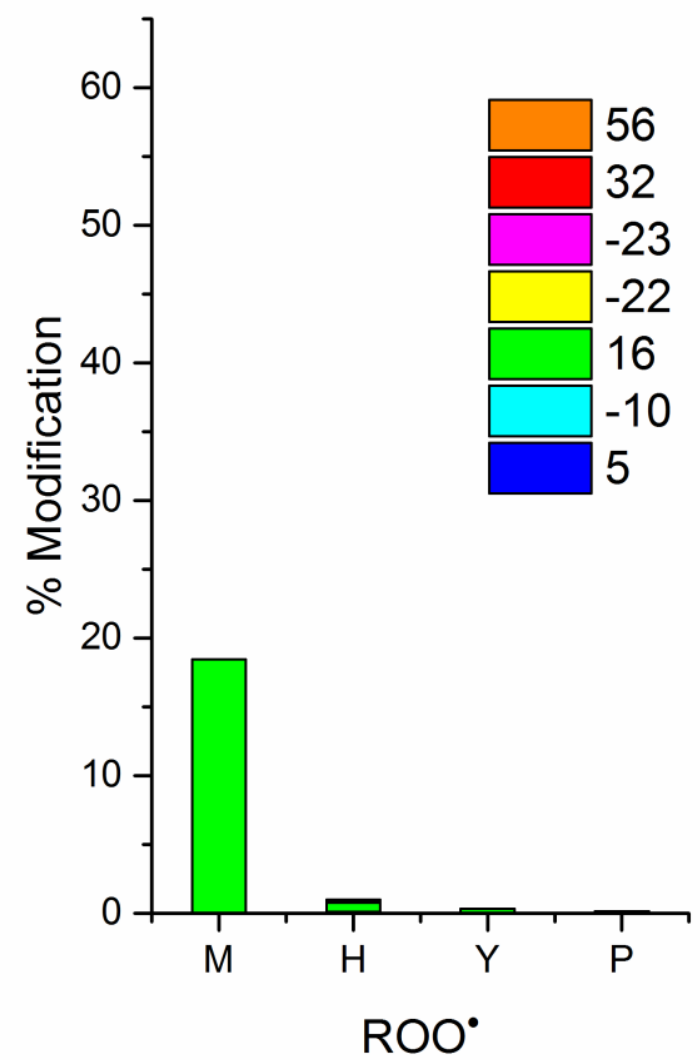




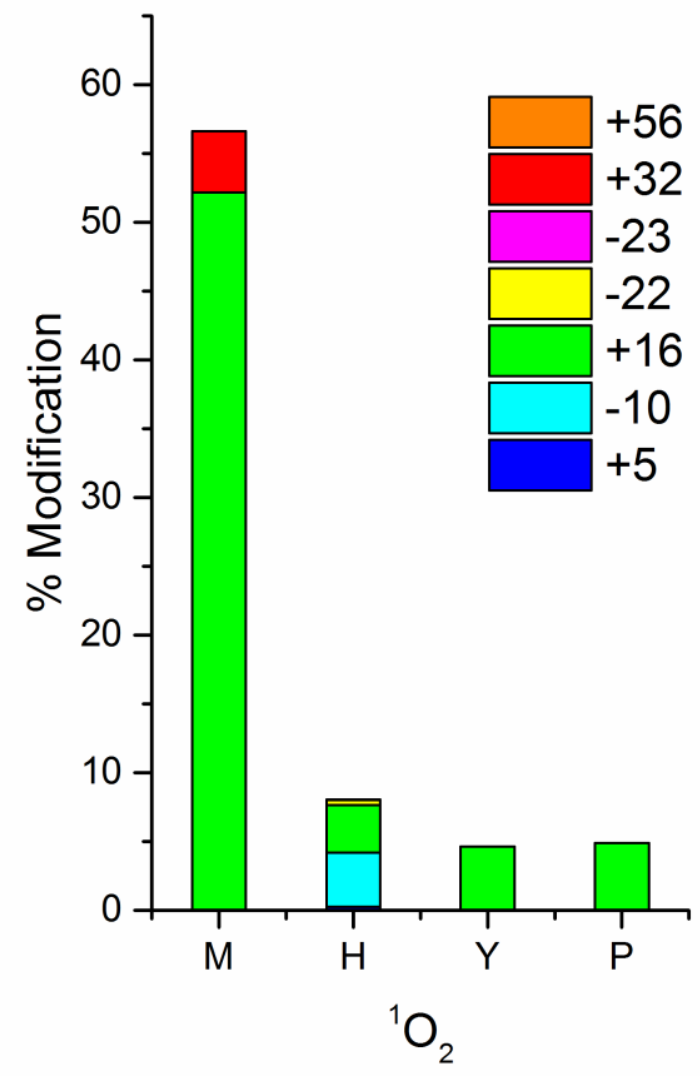




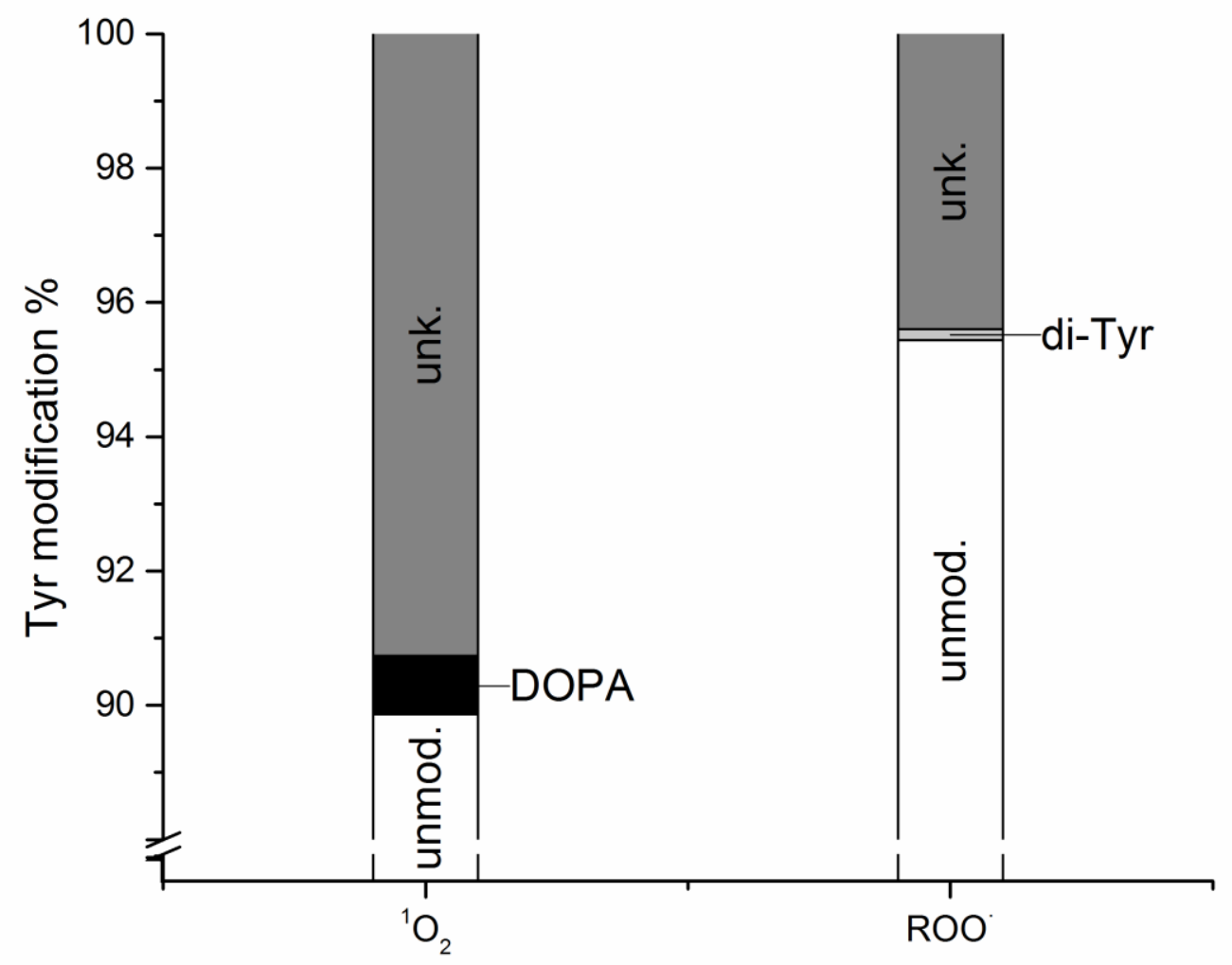



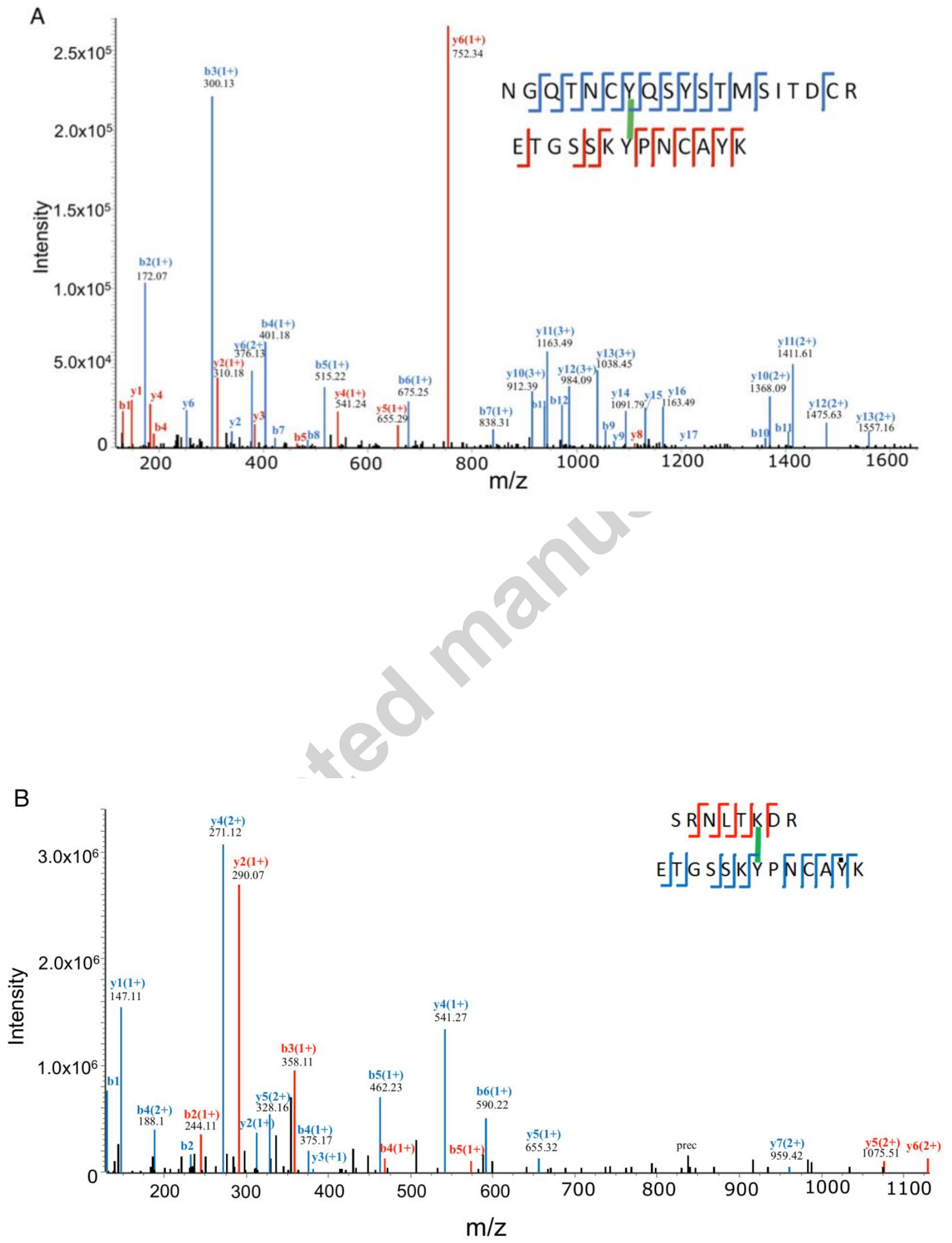


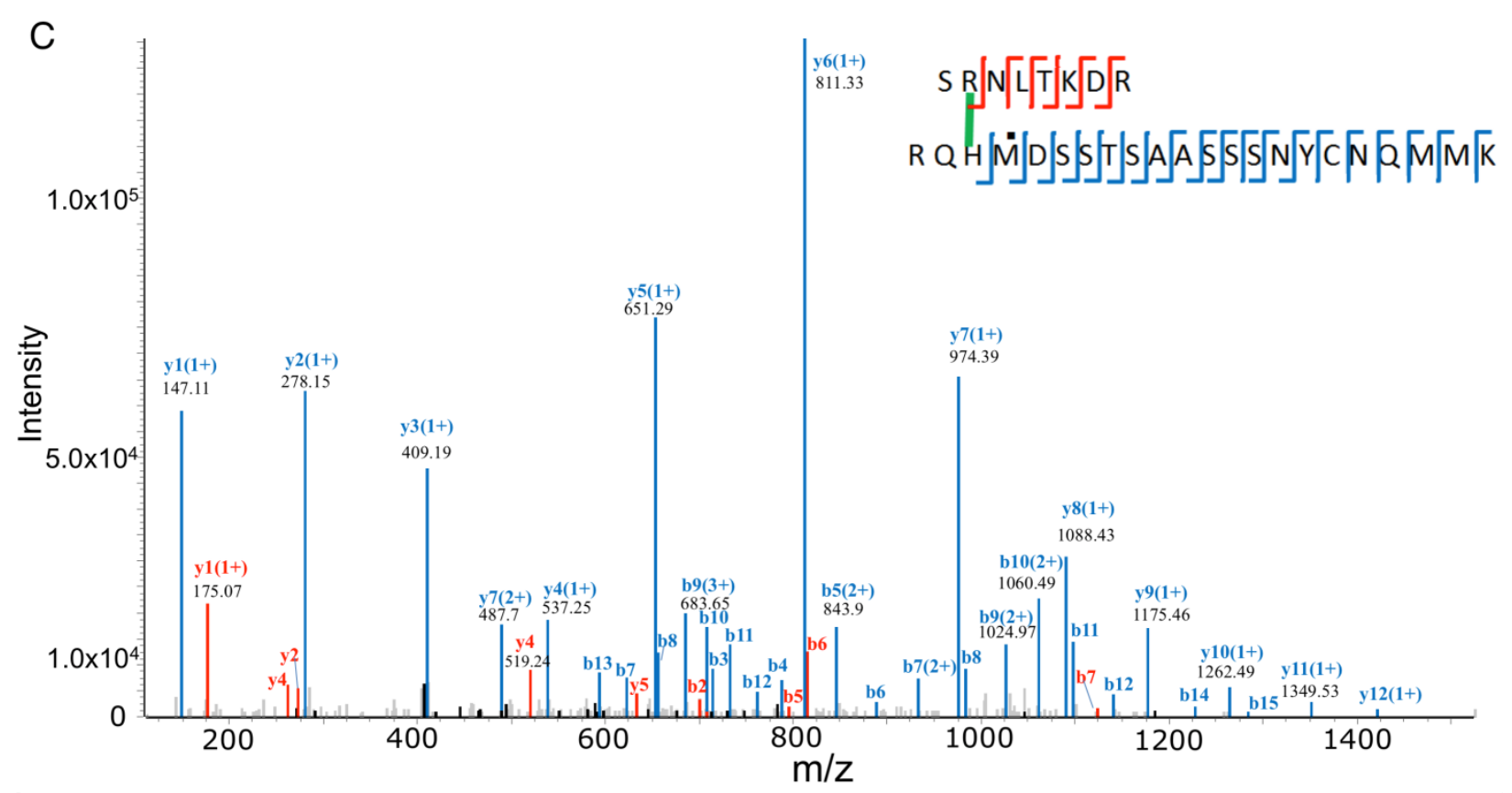




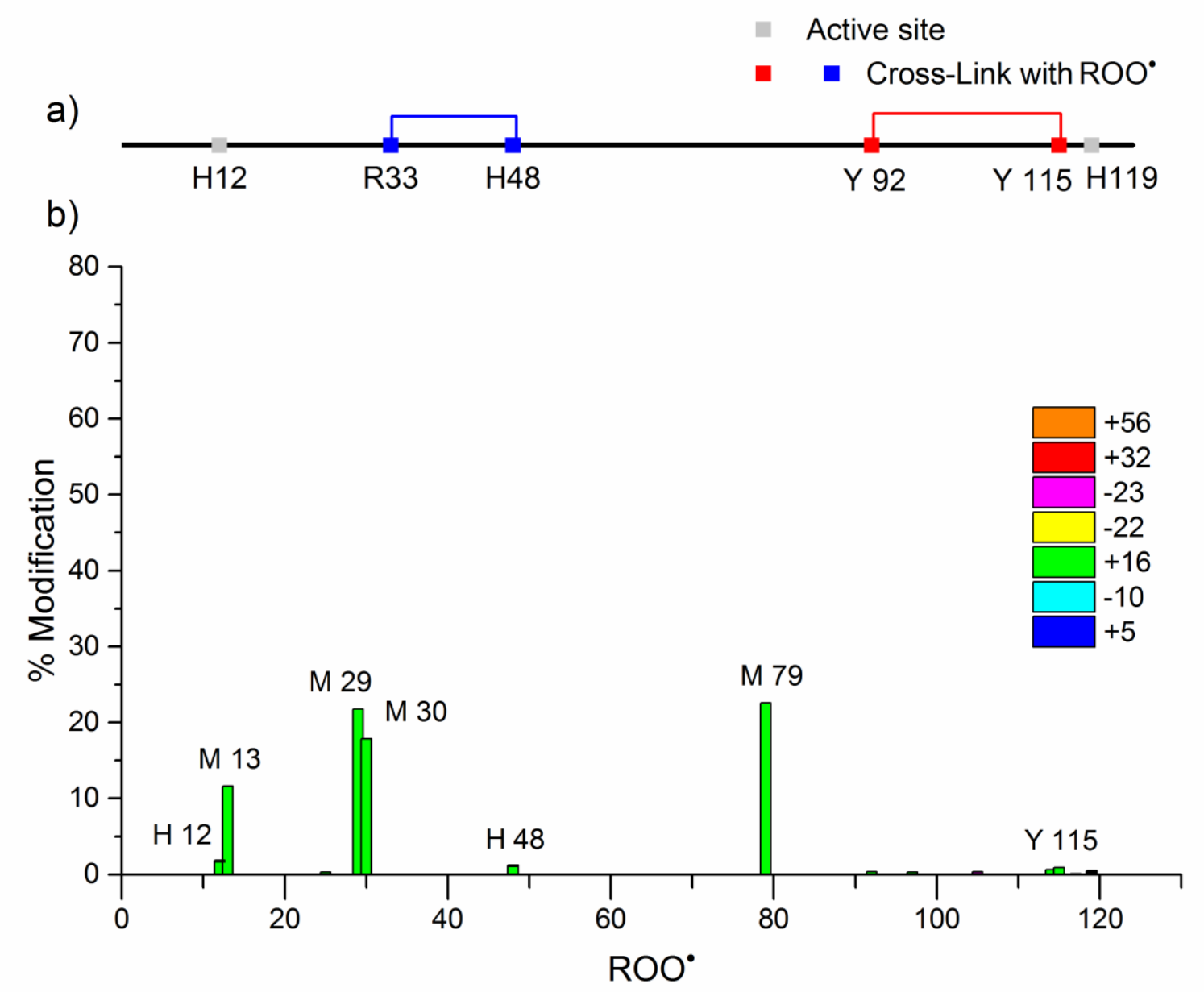




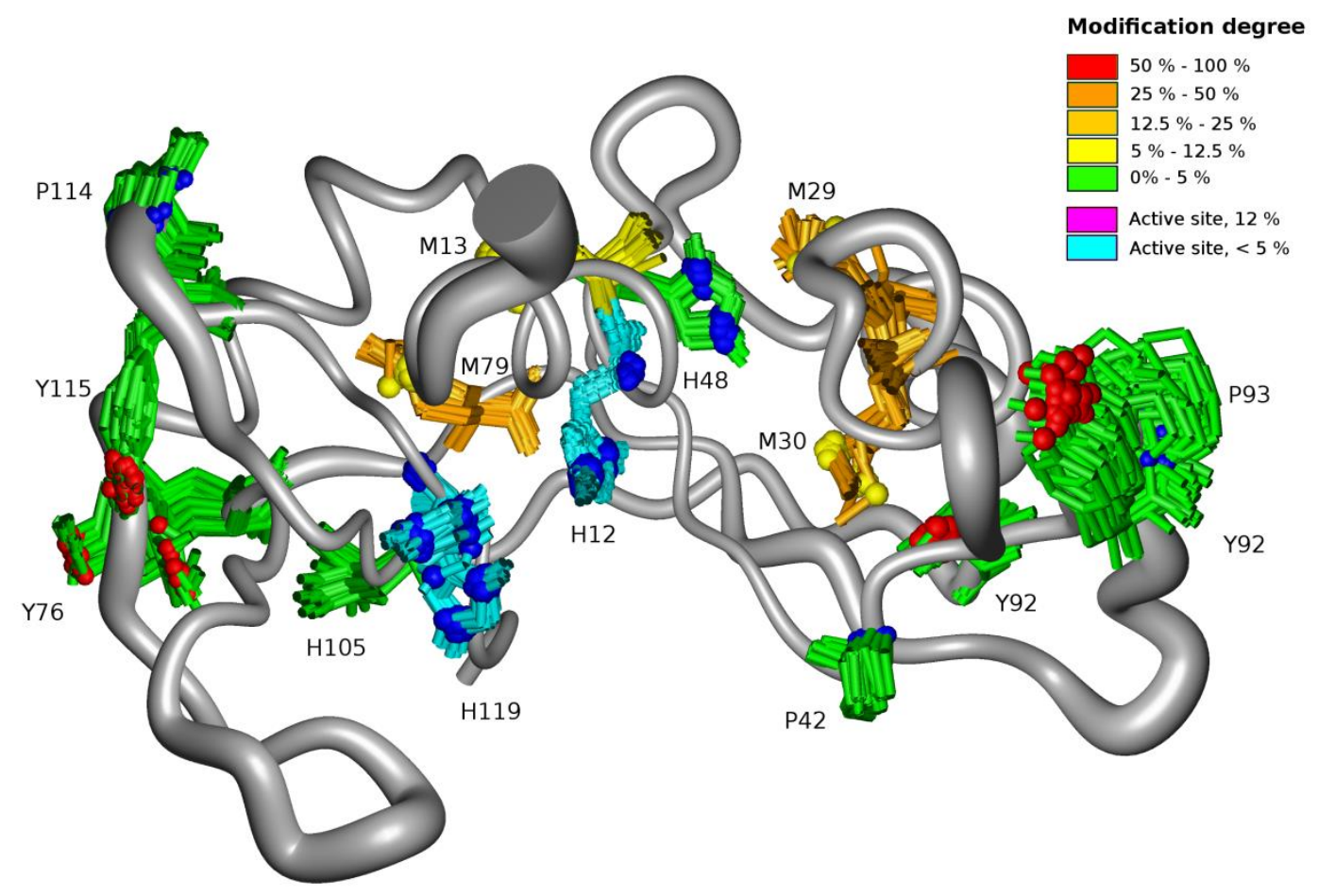




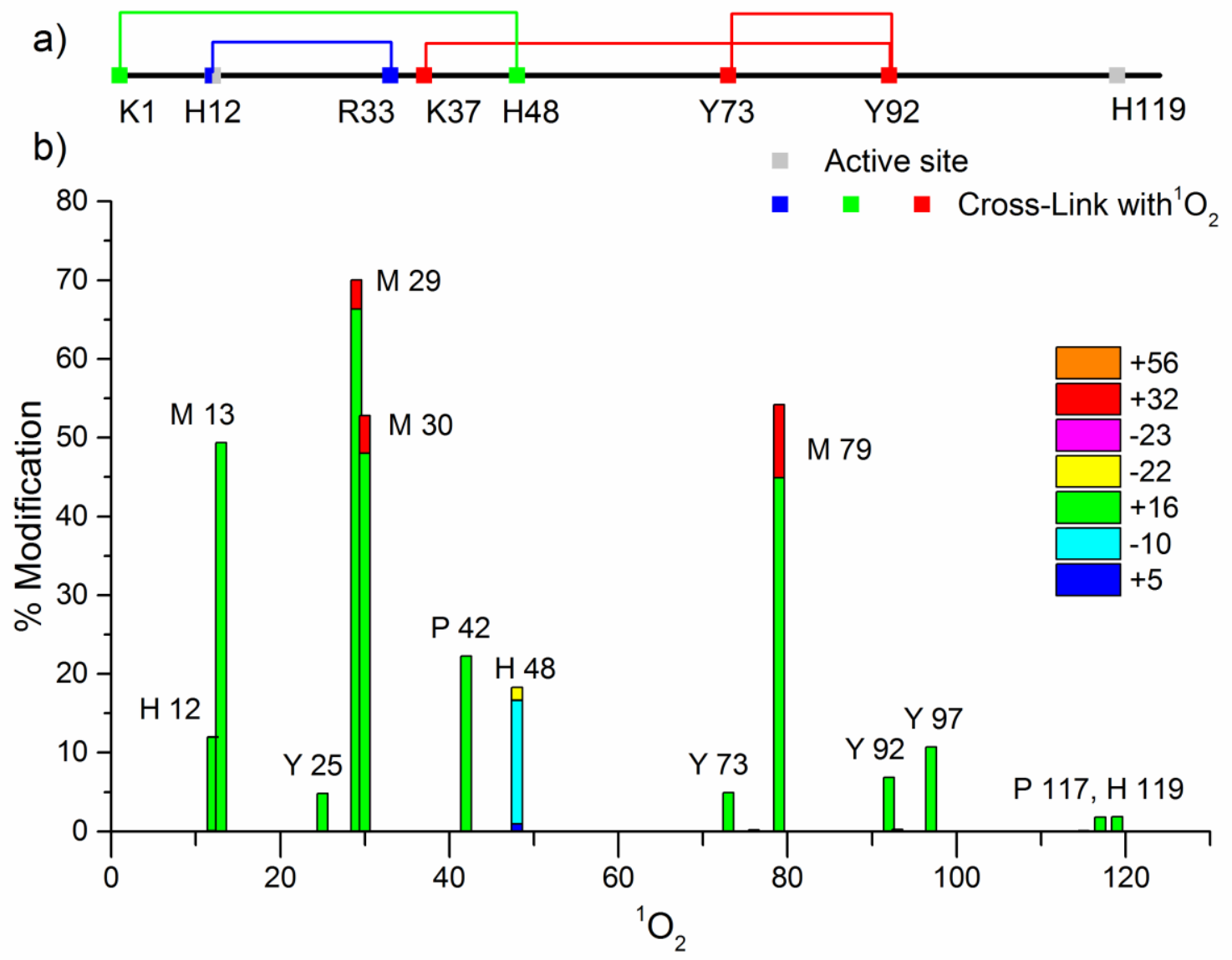




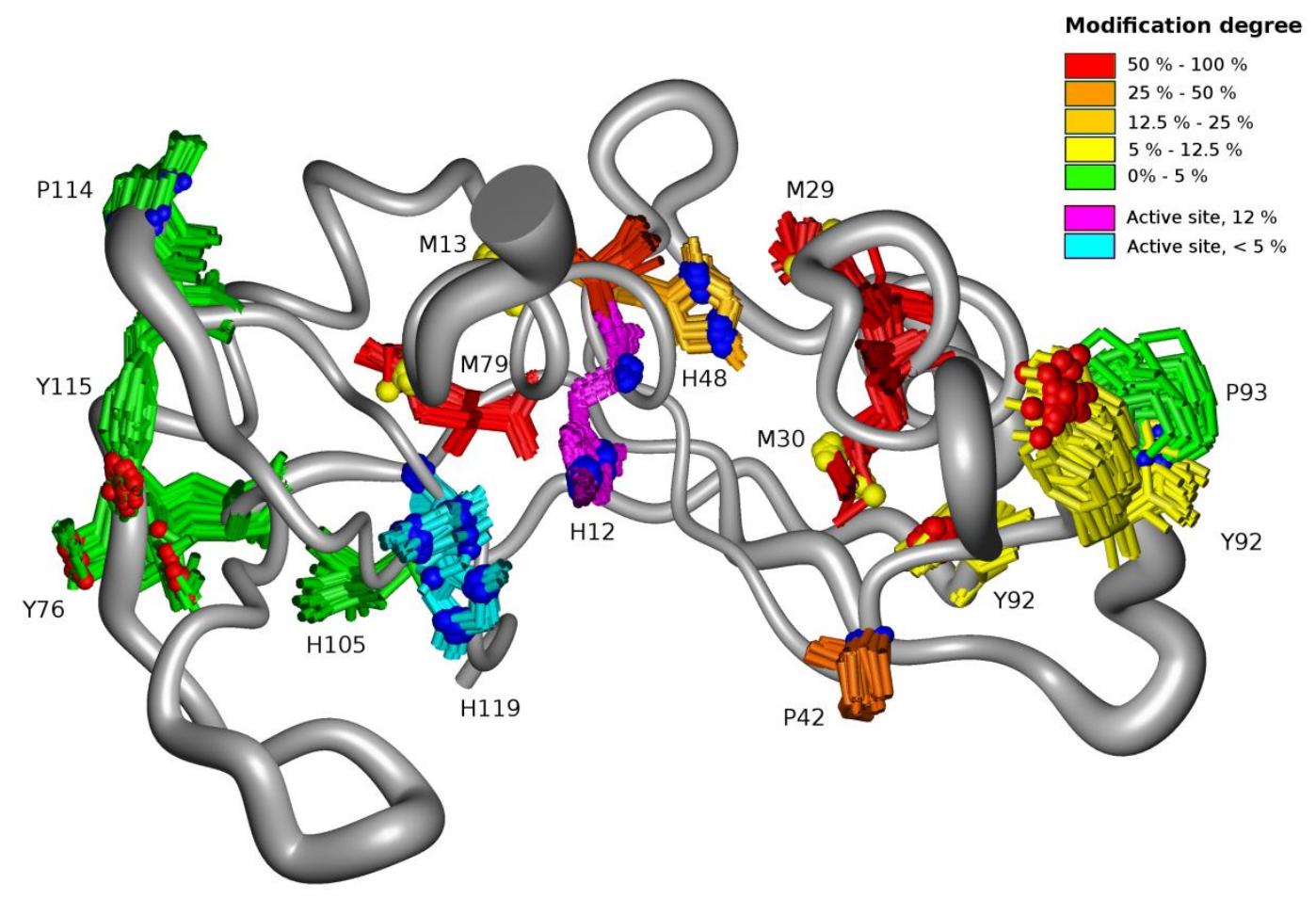


a)

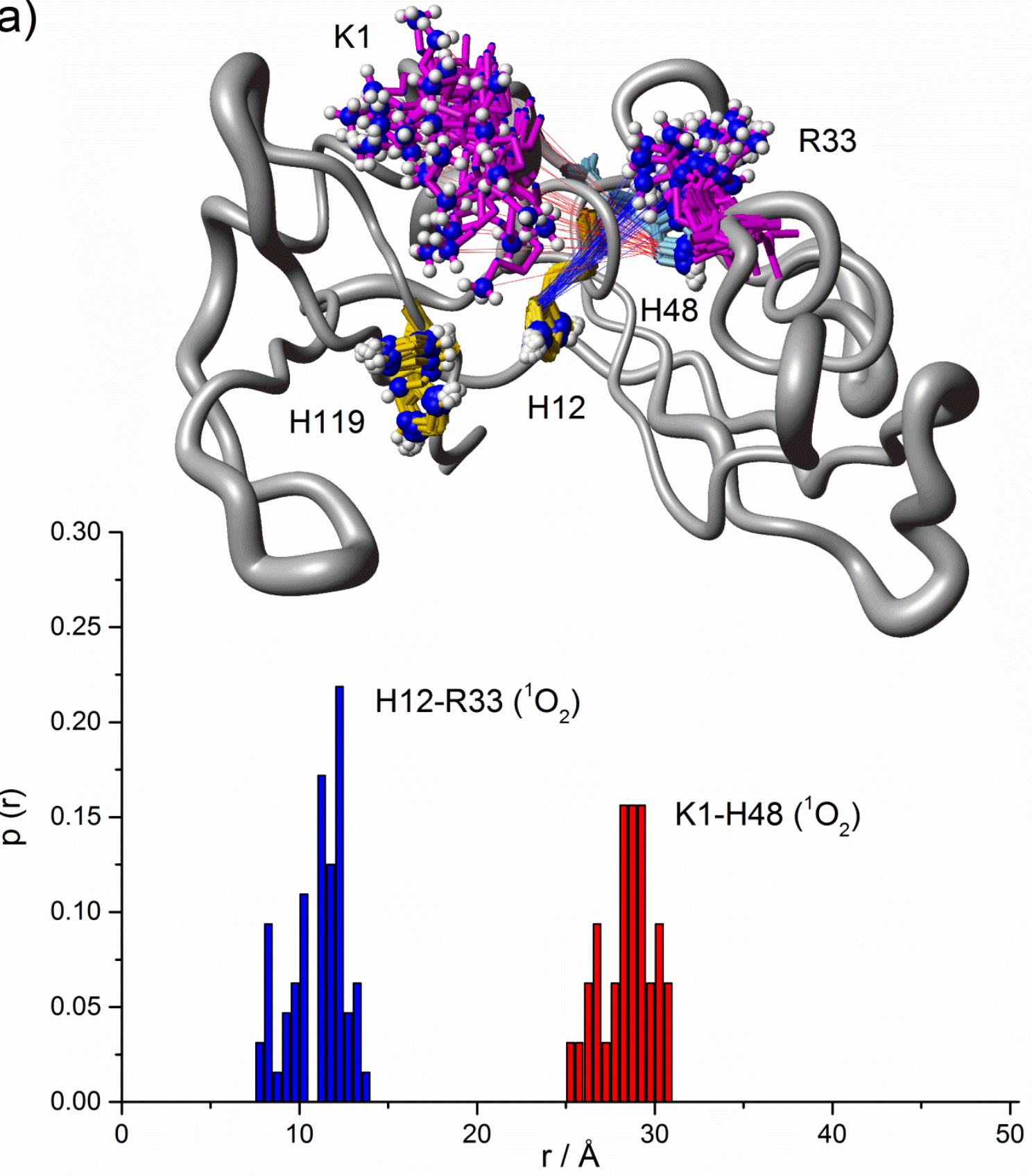


b)

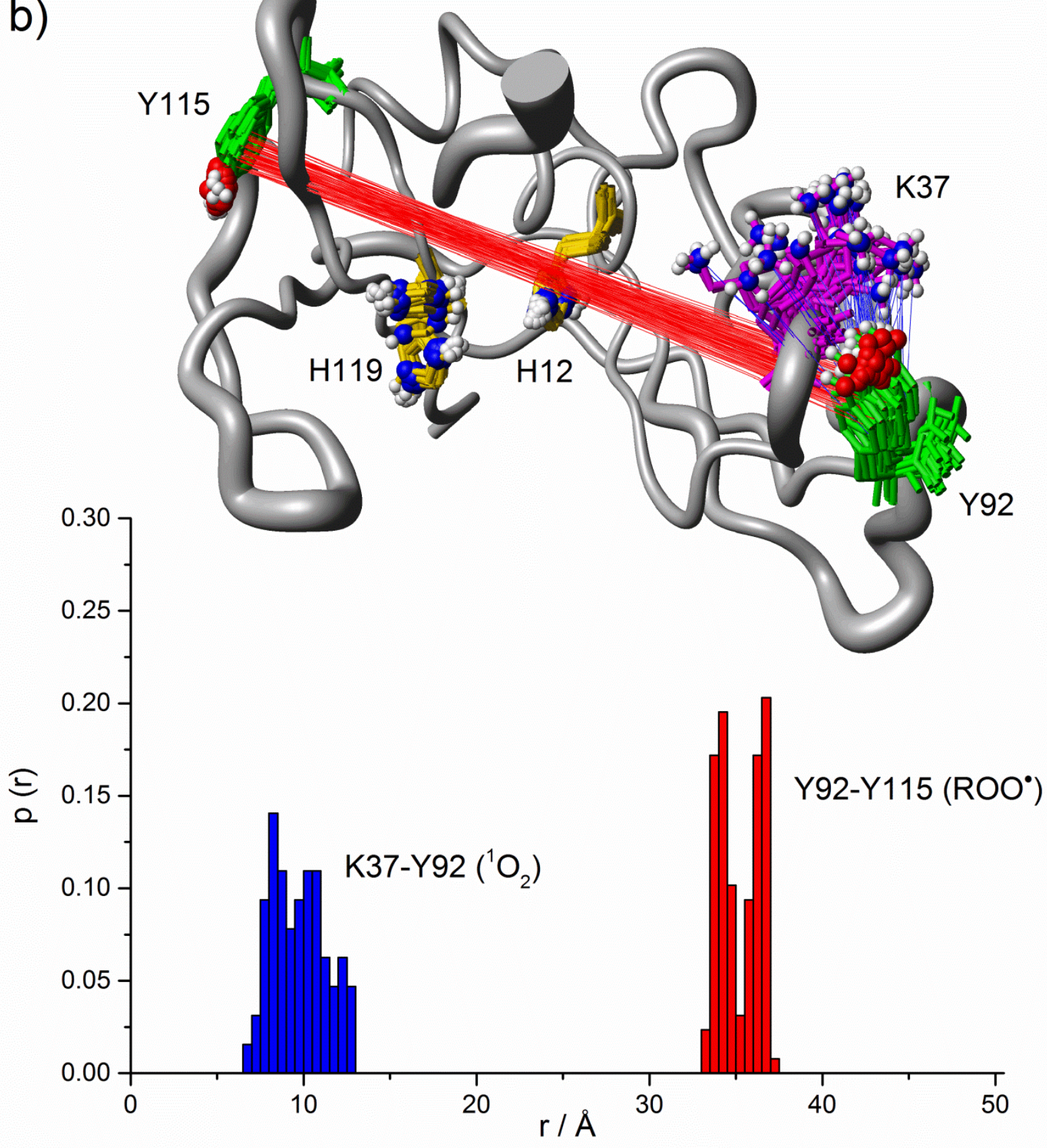




$\begin{array}{ccccc}10 & 20 & 30 & 40 & 50 \\ \text { KETAAAKFERQHMDSSTSAASSSNYCNQMMKSRNLTKDRCKPVNTFVHES } \\ 60 & 70 & 80 & 90 & 100 \\ \text { LADVQAVCSQKNVACKNGQTNCYQSYSTMSITDCRETGSSKYPNCAYKTT } \\ 110 & 120 & & \end{array}$

QANKHIIVACEGNPYVPVHFDASV

a)<smiles>[R]Cc1ccc(O)c(-c2cc(C[R])ccc2O)c1</smiles>

b)<smiles>[R]CCCCNc1cc(O)ccc1C[R]</smiles>

c)<smiles>[R]CCCNC(=N)Nc1nc[nH]c1CC[R]</smiles> 


\section{Highlights}

- RNAse A was oxidized by singlet oxygen $\left({ }^{1} \mathrm{O}_{2}\right)$ and peroxyl radicals (ROO $\left.{ }^{\bullet}\right)$

- ${ }^{1} \mathrm{O}_{2}$, but not $\mathrm{ROO}^{\circ}$, decrease enzymatic activity

- Oxidative modifications have been quantified and mapped to protein sequence

- Met residues are major targets for oxidation, but appear not to be causative for activity loss

- Multiple His- and Tyr-derived cross-links are formed, including active site His-Arg links 